\title{
Thermodynamic Simulation of CCP in Air-Cooled Heat Pump Unit with HFCs and $\mathrm{CO}_{2}$ Trans-Critical
}

\author{
Feihu Chen ${ }^{*}$, Shuguang Liao1, Guangcai Gong2 \\ ${ }^{1}$ Changsha Maxxom High-Tech Co., Ltd., Changsha, China \\ ${ }^{2}$ Civil Engineering College, Hunan University, Changsha, China \\ Email: *maxxom121@163.com
}

How to cite this paper: Chen, F.H., Liao, S.G. and Gong, G.C. (2018) Thermodynamic Simulation of CCP in Air-Cooled Heat Pump Unit with $\mathrm{HFCs}$ and $\mathrm{CO}_{2}$ Trans-Critical. Journal of Power and Energy Engineering, 6, 141-164.

https://doi.org/10.4236/jpee.2018.69012

Received: December 21, 2017

Accepted: September 27, 2018

Published: September 30, 2018

Copyright $\odot 2018$ by authors and Scientific Research Publishing Inc. This work is licensed under the Creative Commons Attribution International License (CC BY 4.0).

http://creativecommons.org/licenses/by/4.0/

\begin{abstract}
The exergy analysis and finite time thermodynamic methods had been employed to analyze the compound condensation process (CCP). It was based on the air-cooling heat pump unit. The cooling capacity of the chiller unit is about $1 \mathrm{~kW}$, and the work refrigerant is $\mathrm{R} 22 / \mathrm{R} 407 \mathrm{C} / \mathrm{R} 410 \mathrm{~A} / \mathrm{CO}_{2}$. The MATLAB/SIMULINK software was employed to build the simulation model. The thermodynamic simulation model is significant for the optimization of parameters of the unit, such as condensation and evaporation temperature and mass flow of the sanitary hot water and size of hot water storage tank. The COP of the CCP of R410A system is about 3\% - 5\% higher than the CCP of the R22 system, while CCP of the R407C system is a little lower than the $\mathrm{CCP}$ of $\mathrm{R} 22$ system. And the $\mathrm{CCP}$ of $\mathrm{CO}_{2}$ trans-critical system has advantage in the hot supply mode. The simulation method provided a theoretical reference for developing the production of CCP with substitute refrigerant $\mathrm{R} 407 \mathrm{C} / \mathrm{R} 410 \mathrm{~A} / \mathrm{CO}_{2}$.
\end{abstract}

\section{Keywords}

Air-Cooled Heat Pump Unit, Compound Condensation Process (CCP), Exergy Analysis Method, Sanitary Hot Water, MATLAB/SIMULINK Software, Fluorine Substitute Refrigerant R407C/R410A,

Natural Refrigerant $\mathrm{CO}_{2}$

\section{Introduction}

One of the most widely used building heating and cooling equipments in resident in China is the air-cooling heat pump unit. And the compound condensation process (CCP) has been an industrial standard. It includes two parts: one is 
the water cooling + water cooling pattern and the other is the water cooling + air cooling pattern. Then the thermodynamic characteristic of the two condenser condensing system should be studied. There are several researches that have been published by our research group about the former one: a thermodynamic model of an irreversible Carnot Refrigerator with Heat Recovery (CRHR) working between two high temperature reservoirs (THTH and TRTR) and one low temperature heat reservoir (TLTL) has been established in this paper for optimization of allocation of heat transfer areas [1]. The finite time thermodynamics is used to set up the time series simulation model and the software CYCLEPAD is used for the simulation of the compound condensing process [2]. As a result, an upper bound of recoverable condensation heat for the compound condensing process is obtained which is in good agreement with experimental result. And the result is valuable and useful to optimization design of cooling and heating resource systems. The thermodynamic characteristic has been studied in the one stage decentralized chiller in south China with R22 [3].

Due to the environment influence of the traditional refrigerant, the substitute refrigerant which has few or no destroy to the environment is developed. The R22 is the most widely used fluorocarbon refrigerant. Now, there are several substitute refrigerants. As a natural refrigerant, $\mathrm{CO}_{2}$ has become the hotspot of air-conditioner and heat pump because of its good characteristic. Because of the high heat transfer efficiency of the $\mathrm{CO}_{2}$, the $\mathrm{CO}_{2}$ refrigerant system is more compact, and the flow resistance is relatively low, and the cooling capacity per unit volume is large, and the area of the heat transfer is reduced, especially with the research and developing of the micro-channel heat exchanger and the high efficiency compressor, and the space occupy ratio of the single stage cycle has deduced a lot [4]. The air-conditioner sample in the car based on $\mathrm{CO}_{2}$ trans-critical refrigerating cycle was developed by Prof. Lorentzen in Nova Technical University in last $90^{\text {th }}$ [5]. From 1994, many car industry companies in Europe, such as BMW, DAIMLERBNZ, VOLVO and Volkswagen combined with the universities and vehicle air conditioner manufacturers developed the $\mathrm{CO}_{2}$ vehicle air-conditioner system [6]. As to the family use $\mathrm{CO}_{2}$ air-conditional systems, they have been studied and developed by many researchers [7]. But most of them including $\mathrm{CO}_{2}$ automation air conditioner are using the traditional 4 components cycle of the basic refrigerating cycle. Because of the low critical temperature of carbon dioxide $\left(31.1^{\circ} \mathrm{C}\right)$, the working pressure far exceeds the sub-critical cycle. So the compression ratio is low, and the pressure gap is large, which brings problems to the design and sealing of components. At the same time, the exergy loss is very high in the throttle which makes the system efficiency lower than the ordinary refrigerant systems [8]. On the other hand, the cost of the components in the $\mathrm{CO}_{2}$ trans-critical refrigerating cycle is high. There are problems of high pressure resistance, high temperature resistance, prevention and curing the leak of $\mathrm{CO}_{2}$ and reduce friction. These problems are the bottleneck in applying the $\mathrm{CO}_{2}$ trans-critical refrigerating cycle [9]. The heating and cooling performance of the equipment has been compared with $\mathrm{CO}_{2}$ trans-critical, 
HFCs and R22: a performance evaluation of mini-channel parallel flow (MCPF) condenser in residential/commercial refrigeration system has been carried out in calorimeter room with wind tune. The field measurement and modeling results of COP's for HFC and $\mathrm{CO}_{2}$ systems has been compared. The new $\mathrm{CO}_{2}$ systems have higher total COP than HFC systems for outdoor temperatures lower than about $24^{\circ} \mathrm{C}$. The modeling is used to calculate the annual energy use of HFC and new $\mathrm{CO}_{2}$ system in an average size supermarket in Stockholm. The result shows that the new $\mathrm{CO}_{2}$ systems use about 20\% less energy than a typical HFC system [10].

But thermodynamics analysis of the compound condensation process (CCP) with two separate cooling systems, including water-cooling + air-cooling systems, has been seldom investigated so far. Literatures most focus on the single refrigeration cycles. And there are some problems needed further investigation, for example, condensation heat recovery of typical air-cooling heat pump unit and its thermodynamic analysis, etc. So it is meaningful in improving the performance of the CCP system, bringing down the operation cost of the $\mathrm{CO}_{2}$ trans-critical CCP, developing the production with the natural refrigerant $\mathrm{CO}_{2}$ [11]. To analyze the performances of the CCP with $\mathrm{R} 407 \mathrm{C} / \mathrm{R} 410 \mathrm{~A} / \mathrm{CO}_{2}$, a thermodynamic model of two-condenser condensation and dynamic simulation of the air cooled heat pump is needed. The thermodynamic model of two-condenser condensation and the dynamic simulation would be developed. This paper presents a general simulation model for a system supplying sanitary hot water, heating, and cooling loads. A base case is defined, and the model is solved with MATLAB/SIMULINK software. The thermodynamic characteristic of the CCP with air cooled heat pump will be studied. The performance of HFC CCP refrigeration systems and alternative $\mathrm{CO}_{2}$ trans-critical solutions for air cooled heat pump will compare the performance with the R22 system.

\section{Material and Methods}

A air-cooling heat pump unit in resident in south China has been selected as the example. The refrigeration capacity is about $1 \mathrm{~kW}$. The working fluid is R22/R407C/R410A. A sanitary hot water system has been added to the unit at July 2013. And it is part of the whole condensation process. The volume of the sanitary hot tank is $100 \mathrm{~L}$. As shown in Table 1.

The high temperature refrigerant from the compressors passes the sanitary hot water supply system and the ordinary condenser in turn. The sanitary hot water system produces sanitary hot water about $7 \mathrm{~kg} \cdot \mathrm{d}^{-1}$. And the water temperature of the water tank that sent to user can reach to about $53^{\circ} \mathrm{C}$. A conventional system on a T-S diagram is illustrated in Figure 1, as show in Figure 1.

The heat recovery technique AC/HP system analysis is a compound-cooling mode which has been analysis in the paper published.

\section{Theory/Calculation}

\subsection{The Mathematical Model of the CCP}

The total condensation heat can be calculated by: 
Table 1. The operating parameter of the CCP.

\begin{tabular}{ccccc}
\hline Refrigerant & Mass flow $(\mathrm{kg} / \mathrm{s})$ & $\begin{array}{c}\text { Suction pressure } \\
(\mathrm{MPa})\end{array}$ & $\begin{array}{c}\text { Exhaust pressure } \\
(\mathrm{MPa})\end{array}$ & $\begin{array}{c}\text { Exhaust } \\
\text { temperature }\left({ }^{\circ} \mathrm{C}\right)\end{array}$ \\
\hline R22 & 0.26 & 1.0 & 3.1 & 100 \\
R410A & 0.26 & 2.2 & 4.3 & 120 \\
R407C & 0.26 & 0.9 & 3 & 90 \\
\hline
\end{tabular}

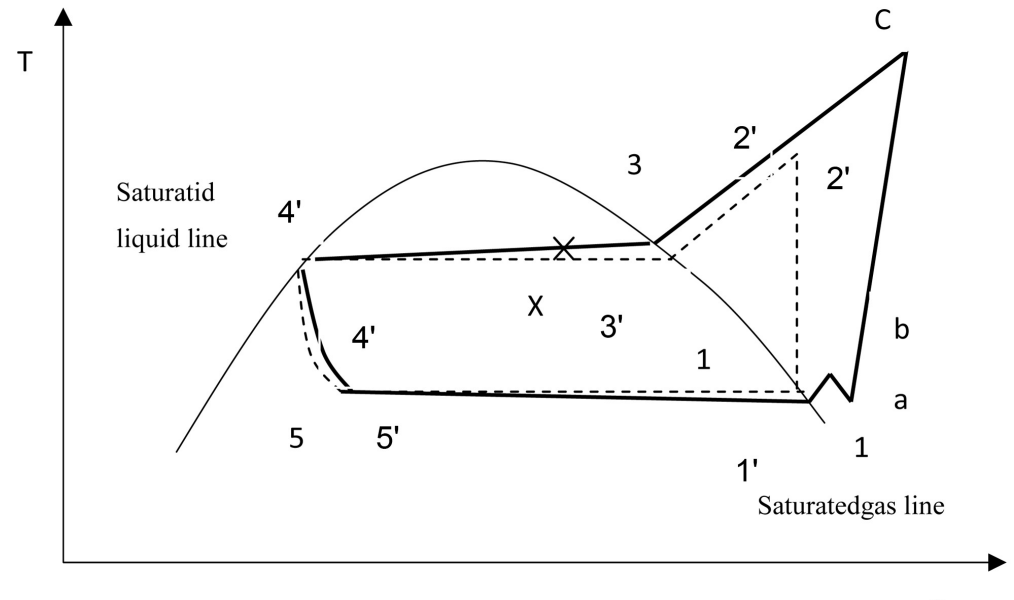

S

Figure 1. The T-S diagram of the air-cooling heat pump unit.

$$
Q_{c}=Q_{\text {cond }}^{\prime}+Q_{\text {cond }}
$$

$Q_{c}$ is total condensation heat;

$Q_{\text {cond }}^{\prime}$ is condensation heat of the sanitary hot water system;

$Q_{\text {cond }}$ is condensation heat of the ordinary condenser.

\subsection{The Mathematical Model of the Sanitary Hot Water System}

The heat recovered by the sanitary hot water system $Q_{\text {shw }}$ is equal to the heat exhausted to the sanitary hot water system $Q_{\text {cond }}^{\prime}$, so:

$$
Q_{\text {cond }}^{\prime}=Q_{\text {shw }}
$$

$Q_{\text {shw }}$ is the heat recovered by the sanitary hot water system.

The exchanged heat of the sanitary hot water system is equal to the enthalpy drop from the state $\mathrm{C}$ to state $\mathrm{X}[12]$ :

$$
\dot{Q}_{\text {cond }}^{\prime}=H_{C}-\dot{H}_{x}
$$

$\dot{Q}_{\text {cond }}^{\prime}$ is the heat exhaust rate to sanitary hot water system [13];

$H_{C}$ is enthalpy at state C;

$\dot{H}_{x}$ is enthalpy at state $\mathrm{X}$;

They are changing corresponding to the heat exchanging condition.

The heat recovered by the sanitary hot water system is calculated by [14].

$$
\dot{Q}_{\text {shw }}=c_{p} \cdot m_{s h w} \cdot\left(\dot{T}_{x}-T_{0}\right)
$$

$Q_{\text {shw }}$ is the heat recovered by the sanitary hot water system; 
$c_{p}$ is special heat capacity of constant pressure;

$m_{\text {shw }}$ is mass flow of sanitary hot water;

$\dot{T}_{x}$ is temperature of the sanitary hot water at the outlet of the sanitary hot water tank;

$T_{0}$ is the initial temperature of the input sanitary hot water.

According to the Equation (3), we can get:

$$
H_{C}-\dot{H}_{X}=C_{P} \cdot m_{s h w} \cdot\left(\dot{T}_{X}-T_{0}\right)
$$

The irreversible exergy loss of the sanitary hot water system is [15]:

$$
\dot{i}_{s h w}=m_{r e f} \cdot T_{0} \cdot\left(\dot{S}_{C}-S_{X}\right)+m_{s h w} \cdot T_{0} \cdot\left(\dot{S}_{X}-S_{0}\right)
$$

$S_{0}$ is the entropy of initial temperature of the input water;

$S_{C}$ is entropy at the state C;

$\dot{S}_{X}$ is entropy at the state X.

The Equation (1), (5), and (6) constitute the mathematical model of the sanitary hot water system.

\subsection{The Mathematical Model of the Ordinary Condenser}

The $Q_{\text {cond }}$ is equal to the enthalpy drop of the refrigerant from state $\mathrm{X}$ to state $4^{\prime}[16]$.

$$
\dot{Q}_{\text {cond }}=\dot{H}_{X}-H_{4^{\prime}}
$$

$H_{4^{\prime}}$ is enthalpy of the refrigerant at state 4 '.

Then, the exergy loss of the ordinary condenser:

$$
\dot{I}_{\text {cond }}=m_{r e f} \cdot\left(\dot{h}_{X}-h_{4^{\prime}}\right)-T_{0}\left(\dot{s}_{x}-s_{4^{\prime}}\right)
$$

$\dot{I}_{\text {cond }}$ is exergy loss rate of the ordinary condenser;

$m_{\text {ref }}$ is mass flow rate of refrigerant;

$S_{4^{\prime}}$ is the entropy of state 4 '.

The Equations (1), (7), and (8) constitute the mathematical model of the ordinary condenser.

The COP and $\eta$ of the CCP are:

$$
\begin{gathered}
\mathrm{COP}=\frac{\sum_{i=1}^{n} \dot{Q}_{c h w i}+\sum_{i=1}^{n} \dot{Q}_{s h w}}{\sum_{i=1}^{n} \dot{W}_{i}} \\
\eta=\frac{\sum_{i=1}^{n} \dot{e}_{c h w i}+\sum_{i=1}^{n} \dot{e}_{s h w}}{\sum_{i=1}^{n} \dot{e}_{w}}
\end{gathered}
$$

COP is energy efficiency of the CCP system;

$\eta$ is exergy efficiency of the CCP system;

$Q_{c h w}$ is the cooling capacity of the chilled water produced;

$E_{c h w}$ is the exergy of the chilled water produced;

$Q_{\text {shw }}$ is the heat of the sanitary hot water produced;

$E_{s h w}$ is the exergy of the sanitary hot water produced;

$E_{w}$ is work input to the CCP. 
The Equations (1), (5)-(10) constitute the mathematical model of the CCP.

\subsection{The Simulation Model of CCP with Simulink}

\subsubsection{The Simulation Model of Hot Water Supply System}

Let $S_{C}$ subtracts $S_{X}$, then the result $\left(S_{C}-S_{X}\right)$ multiplies $T_{0}$ and $m_{\text {ref }}$. The block of exergy loss at refrigerant side $T_{0} \cdot m_{\text {ref }} \cdot\left(S_{C}-S_{X}\right)$ can be gotten. Then do the result add the block of exergy loss at sanitary hot water side $T_{0} \cdot m_{s h w} \cdot\left(S_{X}-S_{0}\right)$, the simulation model of exergy loss of the hot water supply system $m_{r e f} \cdot T_{0} \cdot\left(S_{C}-S_{X}\right)+m_{s h w} \cdot T_{0} \cdot\left(S_{X}-S_{0}\right)$ is gotten. The model shows the process of the refrigerant from state $\mathrm{C}$ to state $\mathrm{X}$ and the water temperature from $T_{0}$ to $T_{X}$, see in Figure 2.

\subsubsection{The Simulation Model of Ordinary Condenser}

According to the outlet pressure of the compressor and the condensing temperature, the $h_{4^{\prime}}$ which is enthalpy of state $4^{\prime}, s_{4^{\prime}}$ which is entropy of state $4^{\prime}$ are gotten. And based on the $T_{X}$ calculated by the model of hot water system above, the $h_{X}$ and $s_{X}$ can be gotten. So the exergy loss of the condenser can be obtained. As shown in Figure 3. The model shows the process from state $\mathrm{X}$ to state 4 'in Figure 1.

\subsubsection{The Simulation Model of the CCP}

The system simulation model consists of these models of compressor, sanitary hot water system, ordinary condenser, expansion valve and evaporator. The operating mode is supplying sanitary hot water and cooling simultaneously. The exergy loss of each component, the exergy of the sanitary hot water and the refrigerate load can be calculated and displayed, as shown in Figure 4.

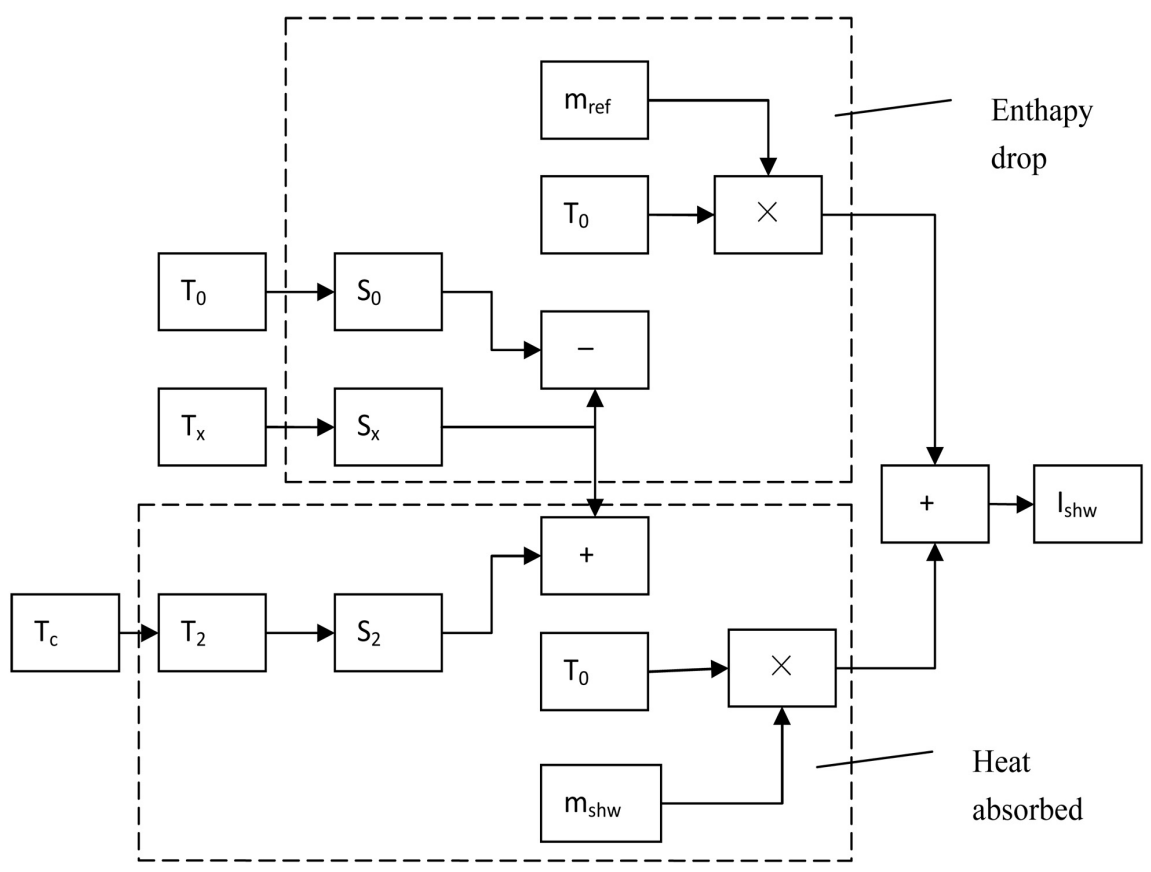

Figure 2. The simulation model of the sanitary hot water system. 


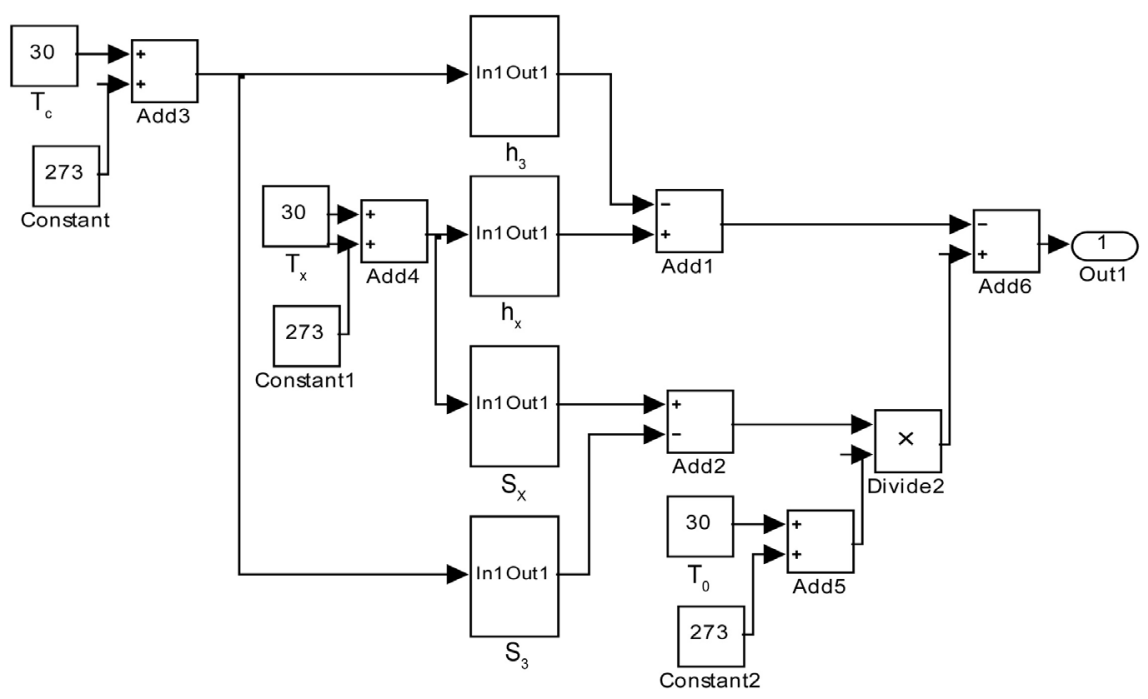

Figure 3. The simulation model of the ordinary condenser.

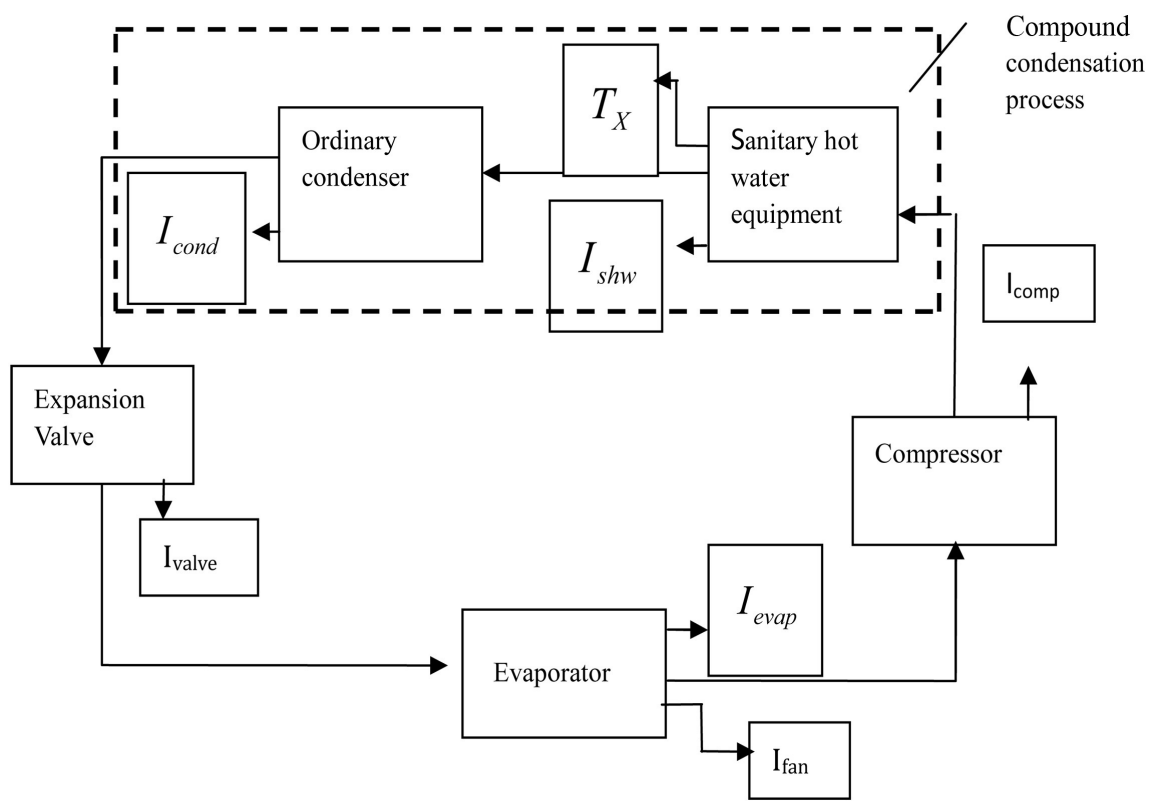

Figure 4. The system simulation model on the refrigerant-sanitary hot water mode.

\subsection{The $\mathrm{CO}_{2}$ Trans-Critical CCP System}

\subsubsection{The Physical Model of the $\mathrm{CO}_{2}$ Trans-Critical CCP}

A sanitary hot water set has been added in the $\mathrm{CO}_{2}$ trans-critical system, seen in Figure 5. It includes compressor, sanitary hot water set, gas-cooler, expansion valve and evaporator. The low pressure refrigerant gaseous has been compressed to high pressure gaseous refrigerant through the compressor (process 1-2), then exhaust heat to the sanitary hot water set at a constant pressure (process 2-3), the rest condensation heat was exhaust to the gas-cooler at a constant pressure (process 3-4), the next is throttling process by throttle (process 4-5), the last is heat absorption of the low pressure liquid refrigerant in the evaporator at a constant pressure (process 5-1). 


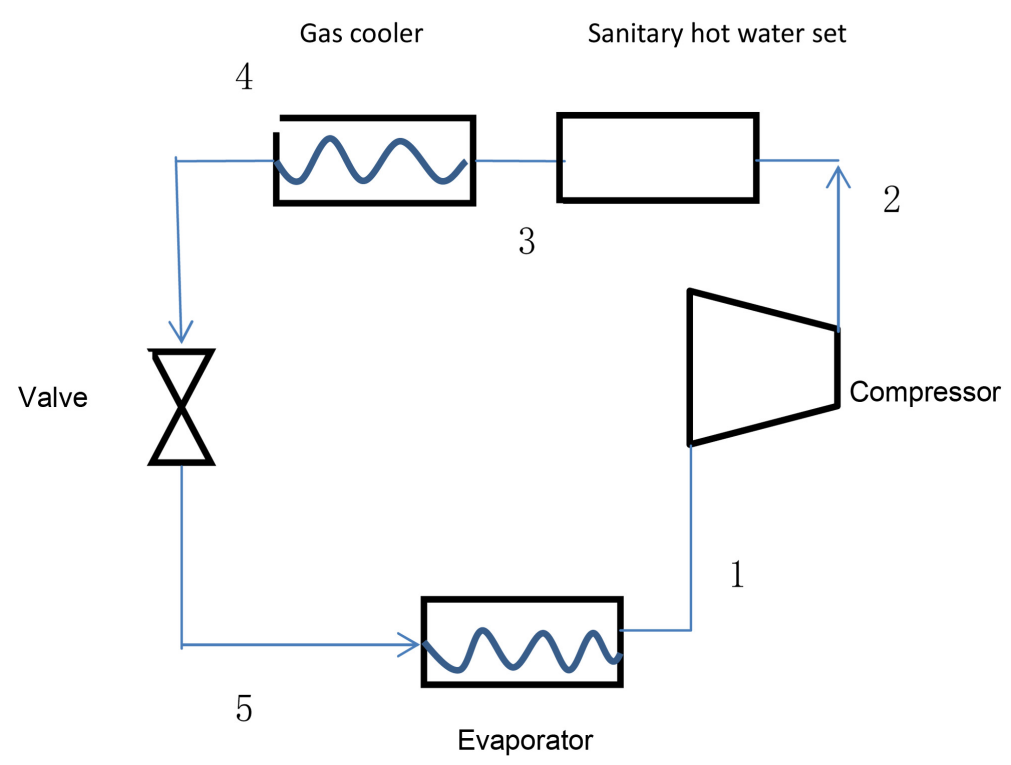

Figure 5. The diagram of the $\mathrm{CO}_{2}$ trans-critical of CCP system.

\subsubsection{The Mathematical Model of the $\mathrm{CO}_{2}$ Trans-Critical CPP}

1) The mathematical model of the compressor

Because of the in-reversible of the compression process, there is entropy and exergy loss produced, according to the T-S diagram of the $\mathrm{CO}_{2}$, seen in Figure 6, the mathematical model can be indicated by:

The work input of the compressor:

$$
W_{a}=\left(h_{2}-h_{1}\right)-\left(h_{3}-h_{4}\right)
$$

In the equation, $W_{a}$ is work input of the compressor; $h_{1}, h_{2}, h_{3}$ and $h_{4}$ are specific enthalpy from state 1 to 4 .

2) The mathematical model of the sanitary hot water set

The calculation period is the time of temperature increase of the hot water tank, which is from the initial temperature to the temperature that the user demand. To the number $i$ cycle, the heat recovered and the exergy loss of the sanitary hot water set and the gas cooler can be calculated by the formula:

$$
Q_{\text {refi }}=Q_{\text {shwi }}+Q_{\text {hroi }}=m_{r e f} \cdot\left(h_{2}-h_{x i}\right)
$$

The subscript $i$ indicate the number $i$ cycle of the sanitary hot water set, $n$ is the total number of the cycle until the temperature of the sanitary hot water reached the user demand. $Q_{\text {refi }}$ is the heat exhaust by the refrigerant at cycle $i$, $Q_{\text {hroi }}$ is heat exhaust to the environment by the refrigerant, $Q_{\text {shwi }}$ is the heat that the sanitary hot water set absorbed in the cycle $i[17] . m_{\text {ref }}$ is the mass flow of the refrigerant $\mathrm{CO}_{2}, h_{X i}$ is special enthalpy of the state $\mathrm{X}$ at cycle $i$.

$Q_{\text {shwi }}$ can be calculated by:

$$
Q_{\text {shwi }}=C_{p w} \cdot m_{s h w} \cdot\left(T_{i}-T_{i-1}\right)
$$

$C_{p w}$ is the specific heat of the refrigerant $\mathrm{CO}_{2}$ at a constant pressure; $m_{r e f}$ is the mass flow of the sanitary hot water; $T_{i}$ is the temperature of the sanitary 


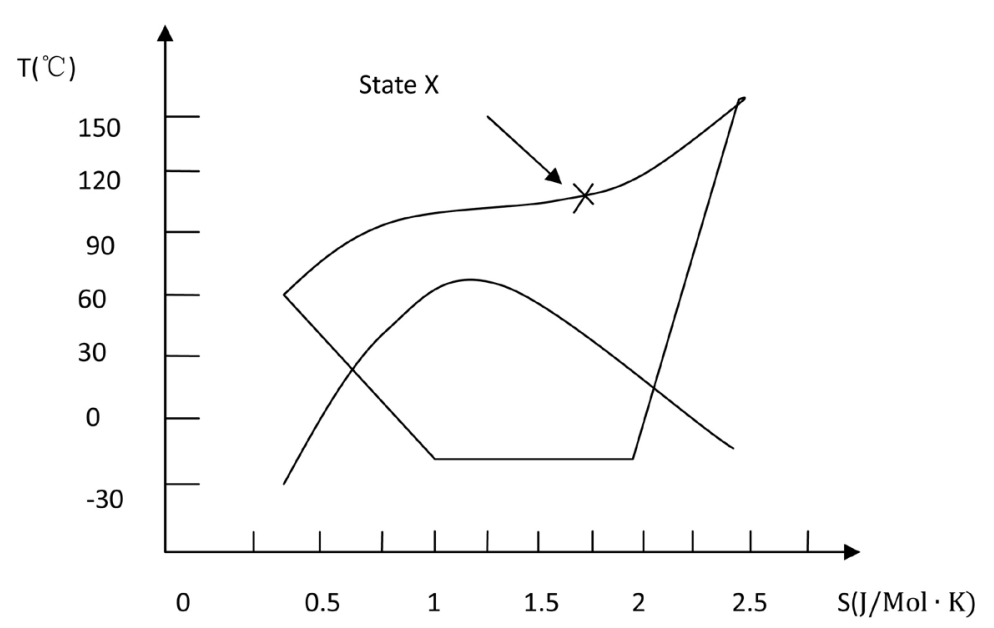

Figure 6. The T-S diagram of the $\mathrm{CO}_{2}$ trans-critical of CCP system.

hot water at cycle i. $T_{0}$ is the initial temperature, $25^{\circ} \mathrm{C}$ [18]. The heat exhaust to the environment is very small and it can be neglected, the heat absorbed by the sanitary hot water is equal to the enthalpy from state $\mathrm{C}$ to state $X$ :

$$
Q_{\text {shwi }}=H_{2}-H_{X i}
$$

$H_{X i}$ is the enthalpy of the state 2; $H_{X i}$ is the enthalpy of the state $X$ at cycle $i$, The initial temperature of $X_{0}$ is equal to $T_{0}, 25^{\circ} \mathrm{C}$, the temperature of the $X_{n}$ is $53^{\circ} \mathrm{C}$.

The exergy loss of the sanitary hot water set can be calculated by:

$$
I_{\text {shwi }}=m_{r e f} \cdot T_{0} \cdot\left(s_{X i}-s_{3}\right)+m_{s h w} \cdot T_{0} \cdot\left(s_{i}-s_{i-1}\right)
$$

$I_{\text {shwi }}$ is the exergy loss of the sanitary hot water set; $s_{X i}$ is entropy of state $X$ at cycle $i ; s_{3}$ is entropy of state $3 ; s_{i}$ is entropy of the sanitary hot water at cycle $i ; s_{0}$ is the entropy of the initial sanitary hot water.

3) The mathematical model of the gas cooler

According to the T-S diagram in Figure 2, the $\mathrm{CO}_{2}$ from the saturated gas to saturated liquid, the dryness from 1 to 0 , use the correlation Dobson, the heat transfer efficiency and pressure drop in the near critical area of the $\mathrm{CO}_{2}$ system can be calculated by [19]:

$$
\begin{gathered}
h=0.023 R_{e l}^{0.8} P_{r l}^{0.4}\left(1+\frac{2.22}{x_{t t}^{0.89}}\right) \frac{\lambda}{d} \\
R_{e l}=\frac{G \cdot(1-x) \cdot d}{\mu_{l}} \\
P_{r l}=\frac{C_{p l} \mu_{l}}{\lambda} \\
x_{t t}=\left(\frac{1-x}{x}\right)^{0.9}\left(\frac{\rho_{v}}{\rho_{l}}\right)^{0.5}\left(\frac{\mu_{l}}{\rho_{v}}\right)^{0.1} \\
\frac{\mathrm{d} P}{\mathrm{~d} L}=\frac{32 G}{R_{e} \cdot \rho \cdot d}
\end{gathered}
$$


In the equations, $\lambda$ is the heat conduction efficiency, $\mathrm{W} \cdot \mathrm{m}^{-1} \cdot \mathrm{k}^{-1}, R_{e l}$ is the Reynard number of the liquid $\mathrm{CO}_{2}, P_{r l}$ is the prandtl number of the liquid $\mathrm{CO}_{2}$; $x_{t t}$ is the turbulence liquid; $C_{p l}$ is the specific heat of the $\mathrm{CO}_{2}, \mathrm{kj} \cdot \mathrm{kg}^{-1} \cdot \mathrm{k}^{-1} ; \mu_{l}$ is the kinetic viscosity of the $\mathrm{CO}_{2} \mathrm{kj} \cdot \mathrm{m}^{-1} \cdot \mathrm{s}^{-1} ; \mathrm{d} P / \mathrm{d} L$ is the pressure drop of the per unit length along the horizontal pipe, bar $\cdot \mathrm{m}^{-1} . R_{e}$ is the Reynard number of the $\mathrm{CO}_{2} ; \rho$ is the mass density of the $\mathrm{CO}_{2}, \mathrm{kj} \cdot \mathrm{m}^{-2}$.

$$
I_{\text {condi }}=m_{\text {ref }} \cdot i_{\text {condi }}
$$

And:

$$
i_{\text {condi }}=\left(h_{X i}-h_{3}\right)-T_{0}\left(s_{X i}-s_{3}\right)
$$

4) The mathematical model of the valve

The exergy loss of the expansion valve is defined by:

$$
I_{\text {exp }}=T_{0} \cdot m_{\text {ref }} \cdot\left(s_{4}-s_{3}\right)
$$

5) The mathematical model of the evaporator

The heat absorb process is happened at the two phase area, and the evaporating pressure is very high, about 7 to 10 times of the ordinary evaporating one, and the physical characteristic is special, so the ebullition heat transfer characteristic is different with the normal refrigerant. So there is different demand in the construction design of the evaporator for the $\mathrm{CO}_{2}$ system [20].

In the $\mathrm{CO}_{2}$ trans-critic water cooling + water cooling heat pump system, the construction of the evaporator is tube and shell, the flow path is double tube side and single shell side. The refrigerant vaporization and absorbed heat in the tube, the chilled water flows at the outside of the tube. There are assumptions: 1) it is steady-state operation; 2) there is no heat conduction at axial direction of the tube; 3) The heat loss is neglect; 4) the $\mathrm{CO}_{2}$ is one-dimensional flow along the axial direction in the tube; 5) the pressure drop is neglect in the chilled water side; 6$)$ the flow and temperature of the $\mathrm{CO}_{2}$ and the chilled water is uniform distribution; 7) the outlet of the evaporator is statute.

When the heat loss is neglect, the heat absorbed of the $\mathrm{CO}_{2}$ in the evaporation is equal to the heat exhaust of the chilled water, according to the heat transfer formula:

1) The heat exhaust at the chilled water side:

$$
Q_{e w}=m_{e v} \times\left(h_{e w, \text { in }}-h_{e w, o u t}\right)=m_{e w} \times C_{p, e w} \times\left(T_{e w, \text { in }}-T_{e w, \text { out }}\right)
$$

In the equation, $Q_{e w}$ is heat exhaust of the chilled water, $\mathrm{W}, m_{e w}$ is mass flow of the chilled water, $\mathrm{kg} \cdot \mathrm{s}^{-1}$, ew, in and ew, out are the entropy at inlet and out let of the chilled water, $\mathrm{j} \cdot \mathrm{kg}^{-1} ; C_{p, e w}$ is the specific heat, $\mathrm{j} \cdot \mathrm{kg}^{-1} \cdot \mathrm{k}^{-1} ; T_{e w, i n}$ and $T_{\text {ew,out }}$ is the temperature at outlet and inlet of the chilled water, $\mathrm{K}$.

2) The heat absorbed by the $\mathrm{CO}_{2}$ :

$$
Q_{e r}=m_{e r} \times\left(h_{e r, \text { in }}-h_{e r, \text { out }}\right)
$$

In the equation, er is heat absorbed by $\mathrm{CO}_{2}, \mathrm{~W}$; er, in and er, out are the enthalpy of the $\mathrm{CO}_{2}$ at inlet and outlet, $\mathrm{j} \cdot \mathrm{kg}^{-1}$. 
3) The total heat transferred:

$$
Q_{r, w}=U_{e} \times A_{z} \times \Delta T_{m}
$$

$Q_{r, w}$ is the heat exchanged, $\mathrm{W}, U_{e}$ is the heat transfer efficiency, $\mathrm{W} \cdot \mathrm{m}^{-2} \cdot \mathrm{k}^{-1}$; $A_{z}$ is the heat transfer area, $\Delta T_{m}$ is logarithmic heat transfer temperature difference, $\mathrm{K}$.

According to the energy balance equation:

$$
Q_{e w}=Q_{e r}=Q_{r, w}
$$

The exergy loss of the evaporator can be valued as:

$$
I_{e v}=m_{r e f}\left[\left(h_{4}-h_{1}\right)-T_{0}\left(s_{4}-s_{1}\right)\right]+m_{e v, w}\left[\left(h_{e v w o}-h_{e v w i}\right)-T_{0}\left(s_{e v w o}-s_{e v w i}\right)\right]
$$

In the equation, $I_{e v}$ is exergy loss of the evaporator; $m_{e v, w}$ is the mass flow of the sanitary hot water; $h_{\text {evwo }}, h_{\text {evwi }}$ is enthalpy of sanitary hot water in and out; $s_{\text {evwo }}$ and $s_{\text {evwi }}$ are entropy of sanitary hot water in and out.

The range of the evaporating is from $-5^{\circ} \mathrm{C}$ to $5^{\circ} \mathrm{C}$.

\subsubsection{The Simulation Model of the CCP System with $\mathrm{CO}_{2}$ Trans-Critical}

1) The simulation model of the compressor

According to the evaporate temperature $T_{e}$, the entropy of the state $1 s_{1}$ can be gotten. Then, the entropy of state $2 s_{2}$ can be calculated according to the condensation temperature $T_{c}$. On the other hand, the $h_{1}, h_{2}$ and $\left(h_{2}-h_{1}\right)$ can be defined and calculated through the value of $T_{e}, T_{c}$, and the compression efficiency of the compressor $\eta_{i s . c}$. Take the $\left(h_{2}-h_{1}\right)$ sublet the product of $T_{0}$ multi $\left(s_{2}-s_{1}\right)$, the result is $\left(h_{2}-h_{1}\right)-T_{0} \cdot\left(s_{2}-s_{1}\right)$. At last, put the $\left(h_{2}-h_{1}\right)-T_{0}\left(s_{2}-s_{1}\right)$ multi the mass flow of the refrigerant $\mathrm{CO}_{2}$, the exergy loss of the compressor $T_{0} \cdot\left(h_{2}-h_{1}\right)-T_{0} \cdot\left(s_{2}-s_{1}\right)$ is gotten, seen in Figure 7 [21].

2) The simulation model of the sanitary hot water set

Take the environment temperature $20^{\circ} \mathrm{C}$ as the reference temperature, set the initial temperature of the sanitary hot water $20^{\circ} \mathrm{C}$ [22]. According to the

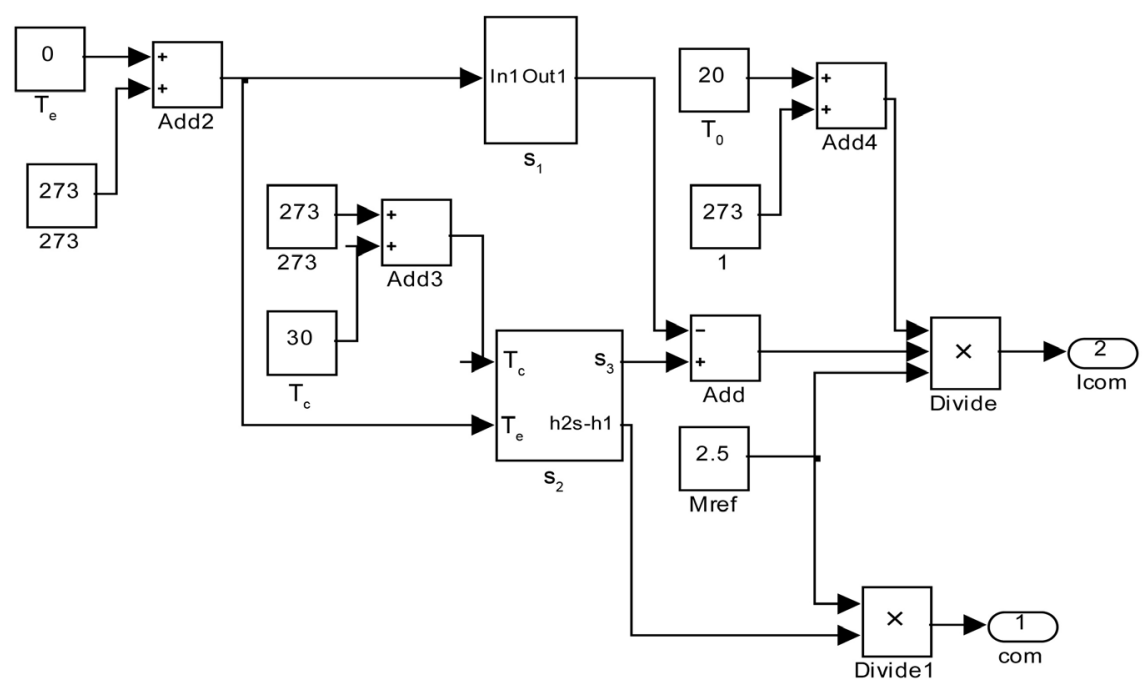

Figure 7. The simulation model of the compressor. 
condensation temperature and evaporation temperature, the entropy of the state 3 can be defined, then, the entropy of the state $\mathrm{X}$ can be calculated. Let the $S_{3}$ sublet $s_{x}$, the result multi the initial temperature $T_{0}$ and the mass flow of the refrigerant $m_{r e f}$. The exergy loss of the refrigerant side $m_{r e f} \cdot T_{0} \cdot\left(s_{3}-s_{X i}\right)$ can be gotten. On the other hand, the mass flow of the sanitary hot water $m_{s h w}$ can be calculated according to the specific of the refrigerant $\mathrm{CO}_{2}$ and the initial temperature $T_{0}$ [22]. To the cycle $i$, take the result of $\left(s_{i}-s_{i-1}\right)$ multi the reference temperature $T_{0}$ and mass flow of the sanitary hot water $m_{s h w}$, the exergy loss of the refrigerant side can be gotten. At last, let the exergy loss of the refrigerant side $m_{r e f} \cdot T_{0} \cdot\left(s_{3}-s_{X i}\right)$ add the exergy loss of the water side $m_{s h w} \cdot T_{0} \cdot\left(s_{i}-s_{i-1}\right)$, the exergy loss can be gotten, the simulation model can be seen in Figure 8 .

3) The simulation model of the gas cooler

According to the exergy loss of the gas cooler $\left(h_{X i}-h_{3}\right)-T_{0}\left(s_{X i}-s_{3}\right)$, at first, the entropy and enthalpy of state $3\left(s_{3}\right),\left(h_{3}\right)$ can be gotten. At the same time, the entropy and enthalpy of state $X, s_{3}, h_{3}$ can be calculated, then through the operation with reference temperature $T_{0}$ and mass flow of the refrigerant $\mathrm{CO}_{2}$ $\left(m_{r e f}\right)$, the exergy loss of the gas cooler can be gotten. See in Figure 9.

The parameter input: the specific of the water is $4.2 \mathrm{kj} \cdot \mathrm{kg}^{-1} ; m_{s h w}$ is mass flow of the sanitary hot water, it is $2.5 \mathrm{~kg} \cdot \mathrm{min}^{-1} ; T_{0}$ is the environment temperature, $25^{\circ} \mathrm{C}$; the adjust parameter: $m_{r e f}$ is the mass flow of the $\mathrm{CO}_{2}$; condensation temperature $T_{C}$ is $100^{\circ} \mathrm{C}[23]$.

4) The simulation model of the valve

According to the exergy loss of the expansion valve: $T_{0} \cdot m_{r e f} \cdot\left(s_{4}-s_{3}\right)$, at first, the entropy of state $4\left(s_{4}\right)$ can be got through the condensation temperature $\left(T_{c}\right)$; then, the entropy of state $3\left(s_{3}\right)$ can be got through the evaporation temperature $\left(T_{e}\right)$; at last, take the different of $\left(s_{4}-s_{3}\right)$ multi the reference temperature $\left(T_{0}\right)$ and mass flow of the refrigerant $\mathrm{CO}_{2}\left(m_{\text {ref }}\right)$. The simulation model of the expansion valve is show in Figure 10.

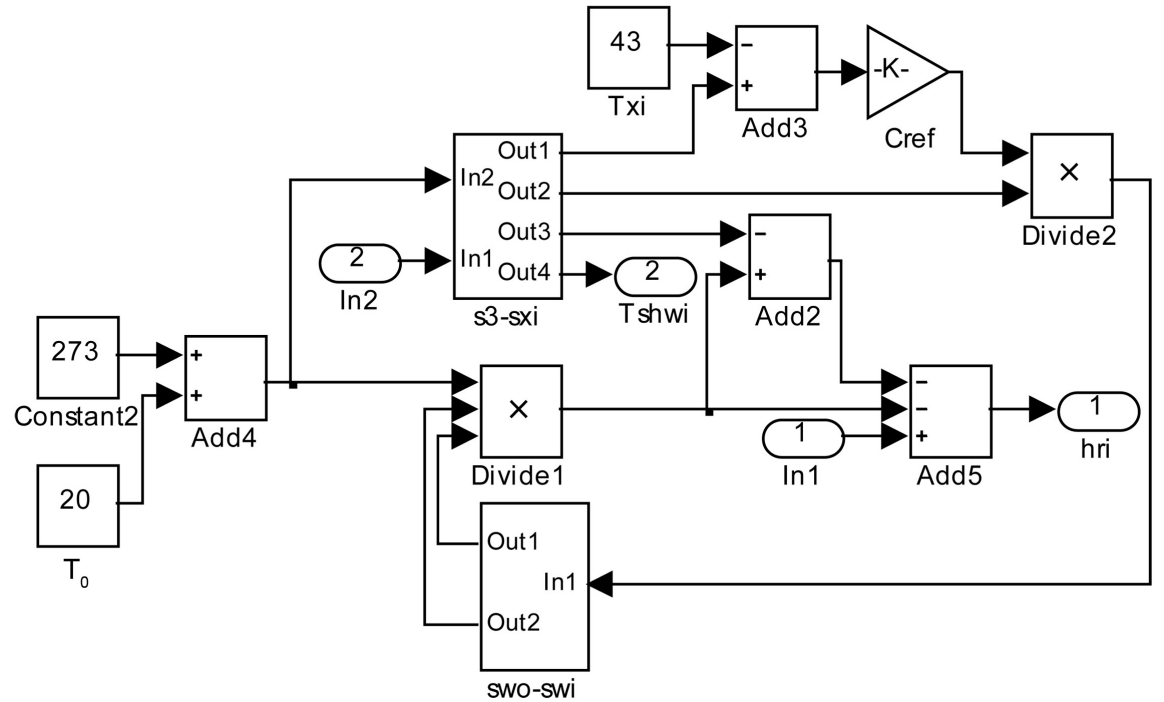

Figure 8. The simulation model of the sanitary hot water set. 


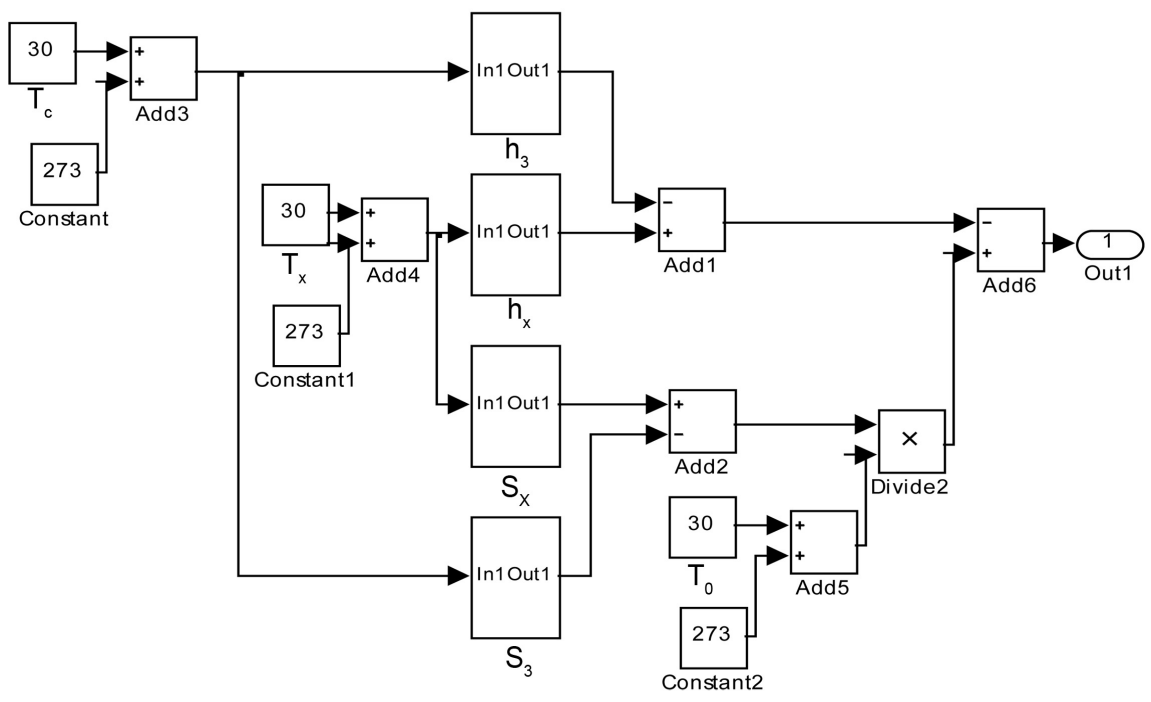

Figure 9. The simulation model of the gas cooler.

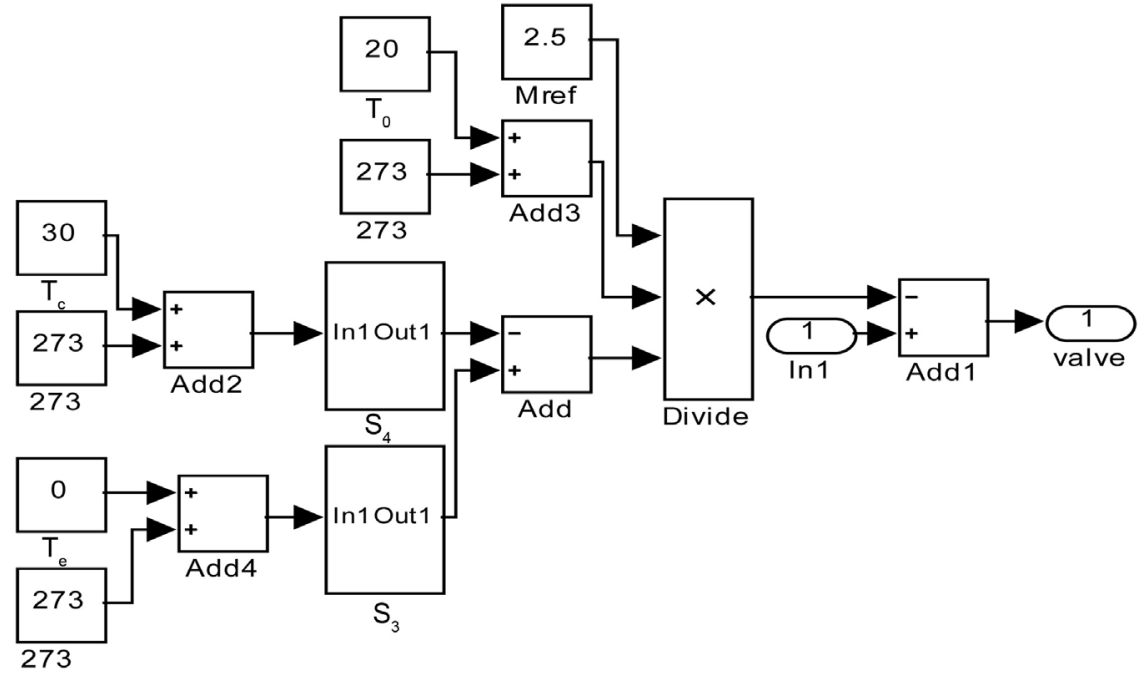

Figure 10. The simulation of the valve.

5) The simulation model of the evaporator

According to the mathematical model of the evaporator, exergy loss of the evaporator is $m_{\text {ref }}\left[\left(h_{4}-h_{1}\right)-T_{0}\left(s_{4}-s_{1}\right)\right]+m_{e v, w}\left[\left(h_{\text {evwo }}-h_{\text {evwi }}\right)-T_{0}\left(s_{\text {evwo }}-s_{\text {evwi }}\right)\right]$. The process of establish the simulation model: at first, according to the condensation and evaporation temperature, the entropy and enthalpy of state 1 and state 4 can be calculated; then, the entropy and enthalpy of inlet and outlet of the sanitary hot water can be defined and calculated. The simulation model can be seen in Figure 11.

6) The simulation model of the CCP with $\mathrm{CO}_{2}$

The simulation model of CCP with $\mathrm{CO}_{2}$ include compressor, sanitary hot water set, air cooled condenser, expansion valve and evaporator. Connected the components to a system model by the MATLAB/SIMULINK software. This model can operate at traditional refrigerating mode (sanitary hot water set shut 


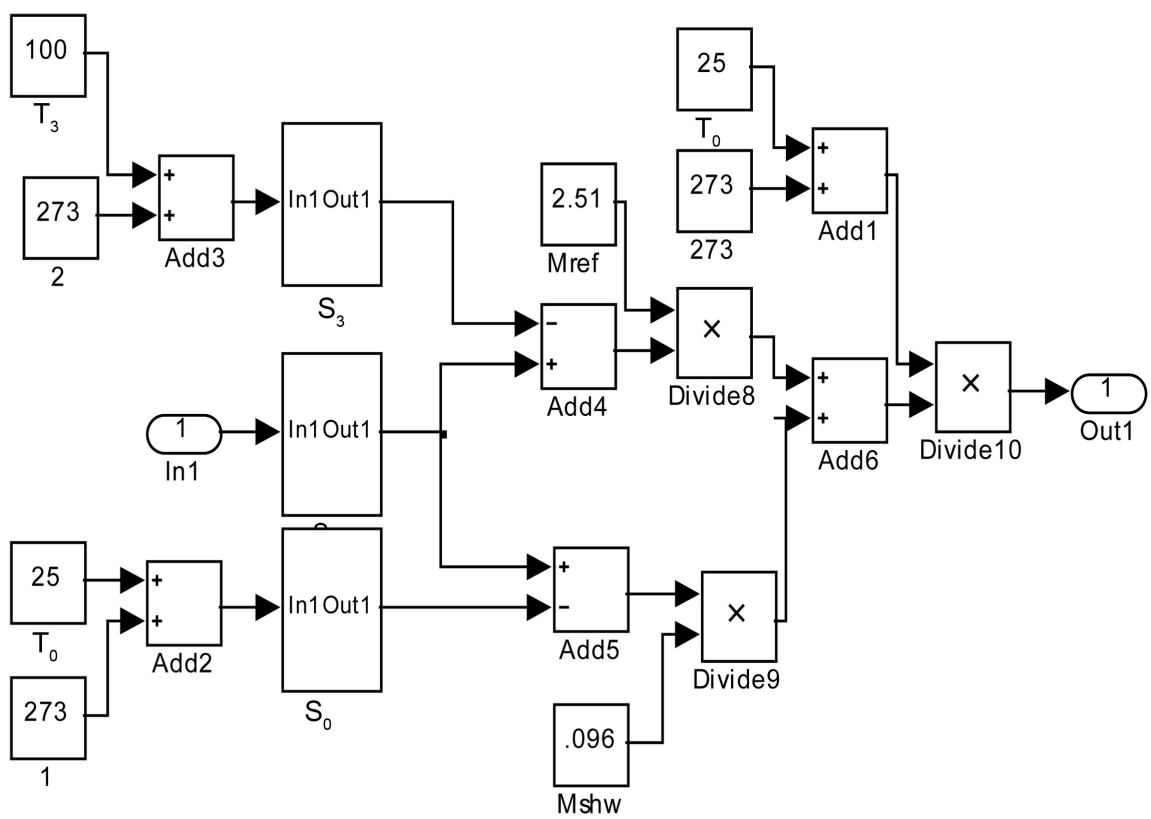

Figure 11. The simulation model of the evaporator.

down) and compound condensation mode. The exergy loss of each component and other parameters can be calculated and displayed, seen in Figure 12.

\section{Results}

Tests of the experimental prototype have been made. The electrical energy input to the prototype compressor is about $1 \mathrm{~kW}$. The charged working fluid is R22. Sanitary hot water tank capacity is $80 \mathrm{~L}$. The rating flux of the water pump for circulation is $2.67 \mathrm{~kg} \cdot \mathrm{min}^{-1}$. The maximal value of the lowest pressure of the compressor suction side is $0.5 \mathrm{MPa}$. The highest pressure of the compressor exit side is $1.8 \mathrm{MPa}$. The water flow and the temperature increasing of the sanitary hot water are assumed to be constant approximately. The energy and exergy efficiency of the system before and after retrofit were investigated. The test data of the operating parameters of the system are plotted in Figure 13 and Figure 14. The relationships of the exergy loss of the component vs. the condensation temperature and evaporation temperature can be seen from Figure 13 and Figure 14.

Figures 15-19 show the operation parameter of the CCP on the refrigeration-sanitary hot water mode. In Figure 15, the exergy loss of the sanitary hot water system is decrease from $0.8 \mathrm{~kW}$ to zero. And the exergy loss of the ordinary condenser increase from 1.4 to $1.6 \mathrm{~kW}$. That is because the heat exchange amount reduces, so the exergy loss reduces accordingly; in the mean while, the heat exchange amount of the ordinary condenser increases, then the exergy loss of the ordinary condenser increases accordingly.

Figure 16 shows the aim exergy efficiency after retrofit and before retrofit. It is showed that the aim exergy efficiency improved 0.05 to 0.01 . That is because the heat transfer temperature difference of the sanitary hot water reduce with the 


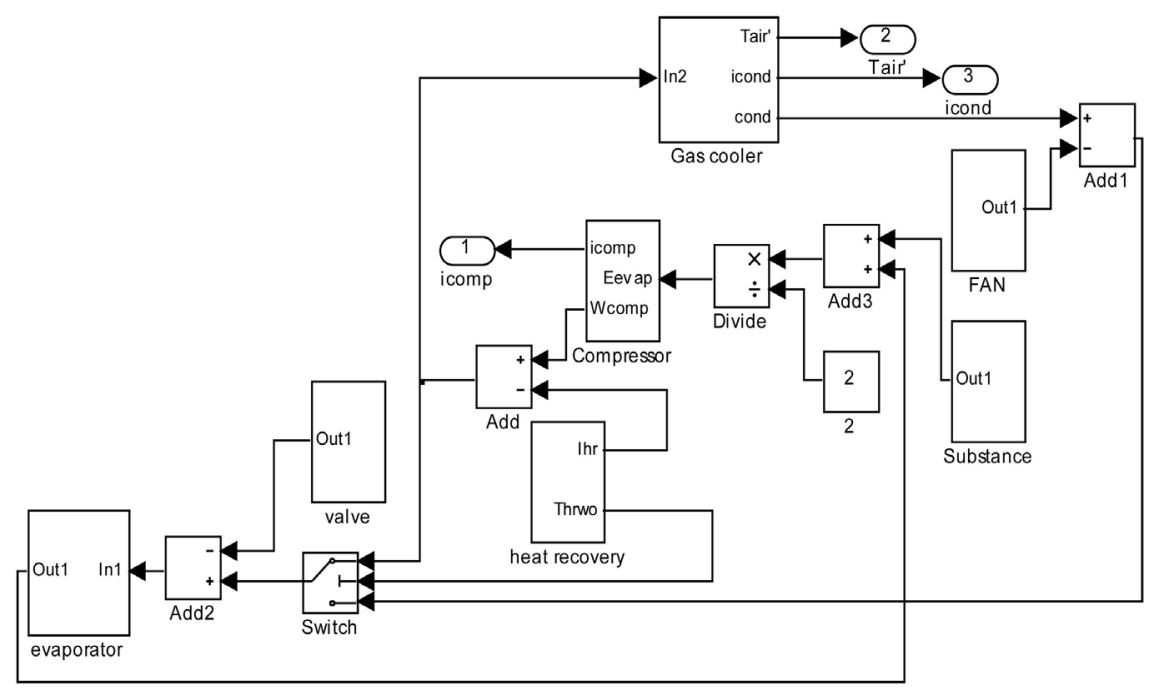

Figure 12. The simulation model of the CCP system with $\mathrm{CO}_{2}$.

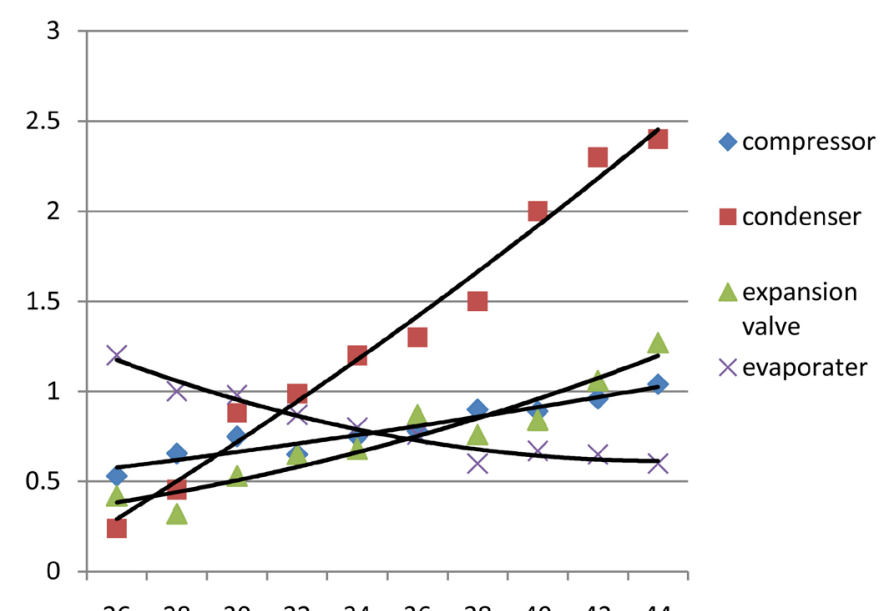

$\begin{array}{llllllllll}26 & 28 & 30 & 32 & 34 & 36 & 38 & 40 & 42 & 44\end{array}$

Figure 13. The exergy loss of the component vs. the condensation temperature at the operation evaporation temperature $0^{\circ} \mathrm{C}$.

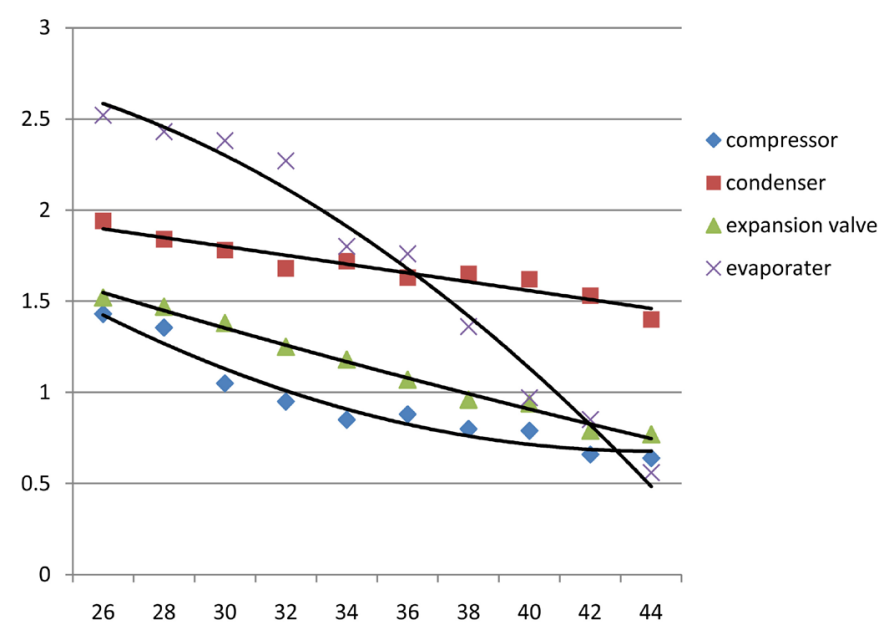

Figure 14. The exergy loss of the component vs. the evaporate temperature at the condensation temperature $40^{\circ} \mathrm{C}$. 


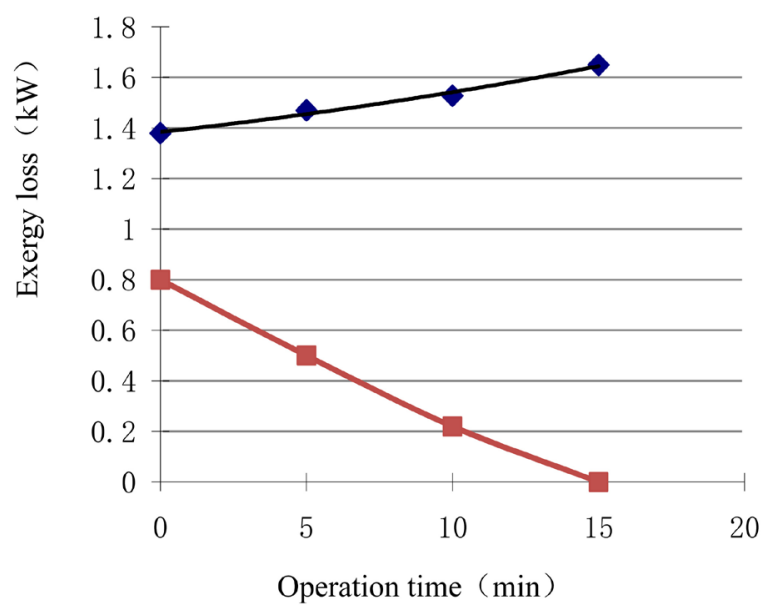

Figure 15. The exergy loss of the air cooled condenser and the heat recovery equipment vs. the operation time (at ambient temperature $25^{\circ} \mathrm{C}$, condensation/evaporation temperature $\left.40 / 0^{\circ} \mathrm{C}\right)$.

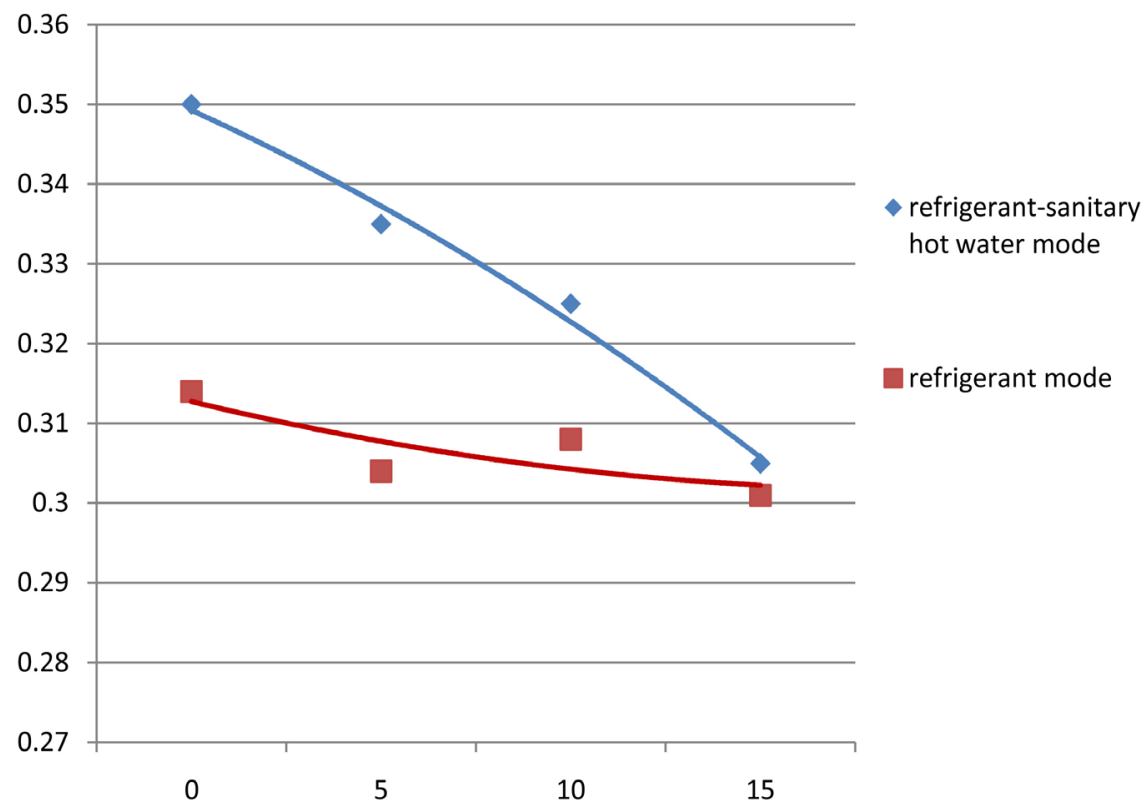

Figure 16. The exergy efficiency vs. the operating time on the refrigerant-sanitary hot water temperature.

increase of the temperature sanitary hot water.

The heat recovered and the exergy efficiency reduce accordingly.

As show in Figure 17, the compare of the COP of CCP and traditional refrigerant mode with R407C, COP of the CCP is vary from 2.7 to 1.9 , and the CCP of the traditional refrigerant mode with $\mathrm{R} 407 \mathrm{C}$ is $1.9-1.8$. The energy using situation has been improved; the thermodynamic characteristic has been increased. In a calculation period, the CCP declined with the operation time. That is because the heat exchange amount is reduced according to the decrease of the temperature gap. The trend is the same with Figure 17. 


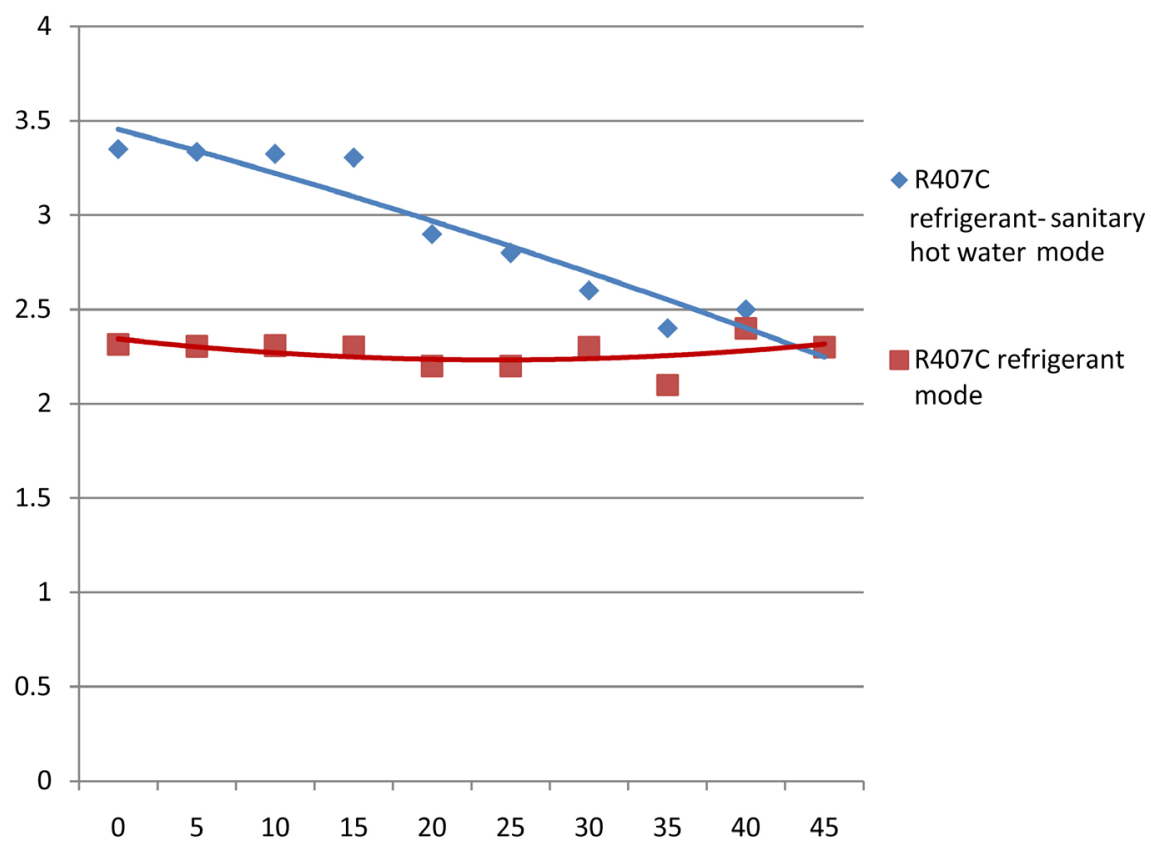

Figure 17. The COP of the CCP and the traditional refrigerant mode with R407C.

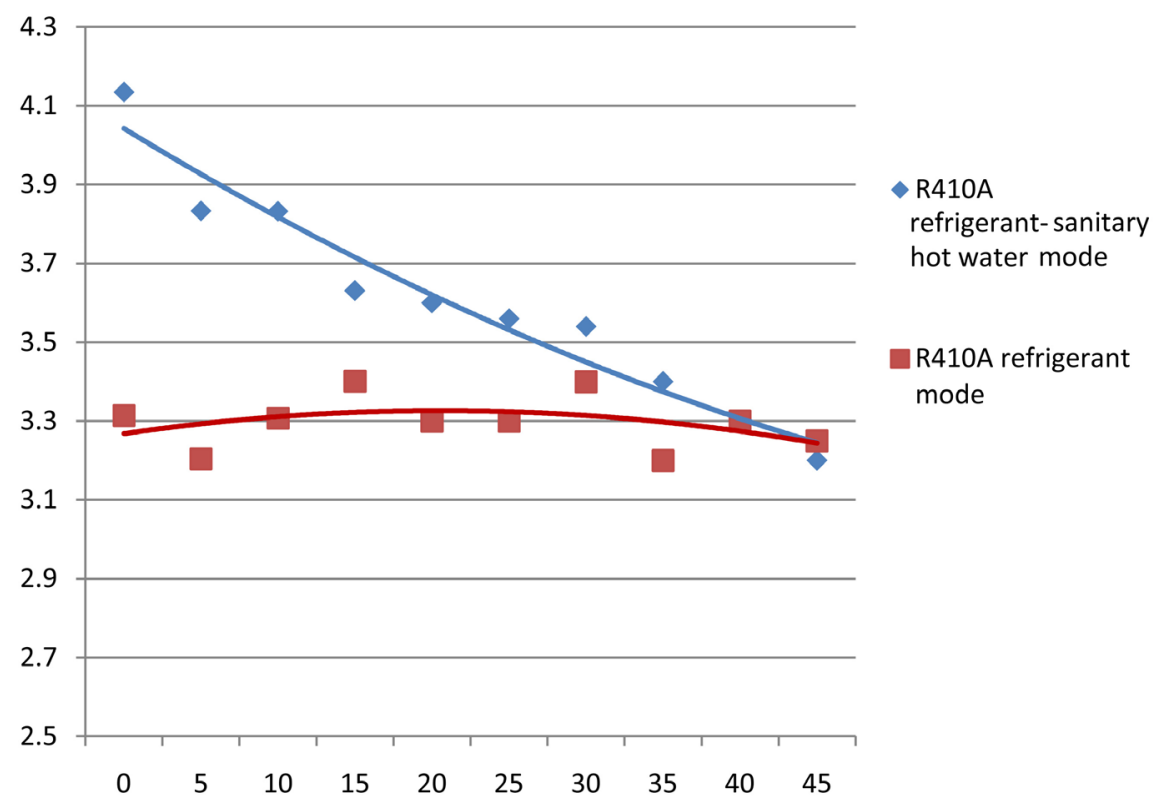

Figure 18. The COP of the R410A refrigerant-sanitary hot water mode vs. refrigerant mode.

As show in Figure 18, it compares the COP with the CCP and the traditional refrigerant mode with R410A. After retrofit, the COP is $3.3-2.3$; it is $2.3-2.2$ before retrofit. The energy using situation is improved, the performance of the COP is enhanced of the COP. the COP declined with the operation time. That is because the heat exchange amount is reduced according to the decrease of the temperature gap. The trend is the same with Figure 17.

As show in Figure 19, the COP of the R410A is about $0.3-0.5$ higher than the 


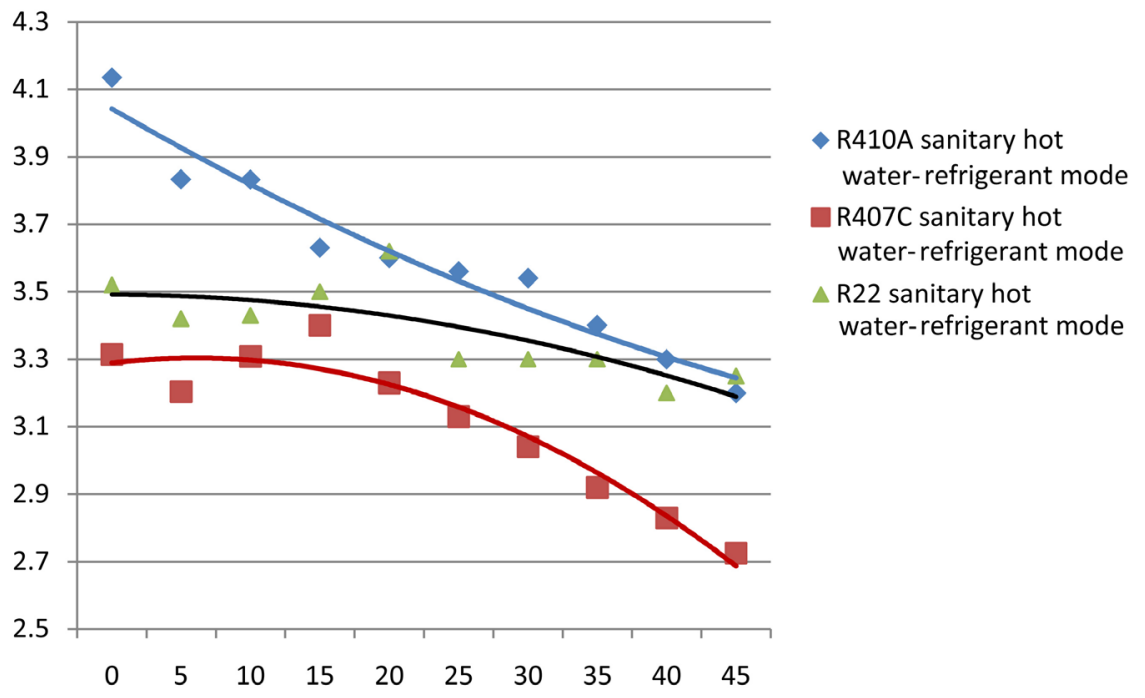

Figure 19. The COP of the CCP with R22/R407C/R410A.

R22 system, the R407C system is about 0.2 lower than the R22 system.

On the sanitary hot water model: the outlet temperature of the sanitary hot water tank of the CCP with the R407C and R410A is showed in Figure 20. The increase velocity of the temperature of the sanitary hot water of the R410A system is the fastest. To the temperature the user demand $47^{\circ} \mathrm{C}$, the $\mathrm{R} 407 \mathrm{C}$ system needs about 27 mins, the R22 system needs about 40 mins, the R410A system needs about 52 mins.

Figure 21 shows the exergy efficiency vs. the temperature of the sanitary hot water that the user demand. The R410A system is $0.2-0.5$ higher than the R22 system. And the R407C system is $0.5-0.1$ lower than the R22 system.

The $\mathrm{COP}$ of the $\mathrm{CO}_{2}$ refrigerant mode vs. exhaust pressure. The COP declines with the increase of the exhaust pressure. It is about 3.6 at the exhaust pressure 8.5 $\mathrm{MP}_{\mathrm{a}}$, and declines to 3.3 at the exhaust temperature $10.0 \mathrm{MP}_{\mathrm{a}}$.

Figure 23 shows the COP of CCP system with $\mathrm{CO}_{2}$ vs. the $\mathrm{COP}$ of $\mathrm{CO}_{2}$ refrigerant system. The COP of CCP system declines with the increase of the exhaust pressure. It is about 3.4 at the exhaust pressure $5 \mathrm{MP}_{\mathrm{a}}$, and declines to about 2.4 at exhaust pressure $35 \mathrm{MP}_{\mathrm{a}}$. While the $\mathrm{COP}$ of the $\mathrm{CO}_{2}$ refrigerant system stays about $2.3-2.3$.

The COP of the CCP system with $\mathrm{R} 22$ and $\mathrm{CO}_{2}$ is showed in Figure 24, the $\mathrm{CCP}$ of $\mathrm{CO}_{2}$ system with is lower than the CCP of the R22 system.

From the Figure 25, the outlet temperature of the sanitary hot water tank, it shows that it needs 18 minutes to reach the temperature that the user demand. And the R22 system is about 30 minutes.

\section{Discussion}

The simulation model of the CCP with refrigerant R22/R407C/R410A/CO for periods of 18 - 30 minutes were built, the object is water cooling + air-cooling combined heat pump system for a typical resident in south China. The refrigeration 


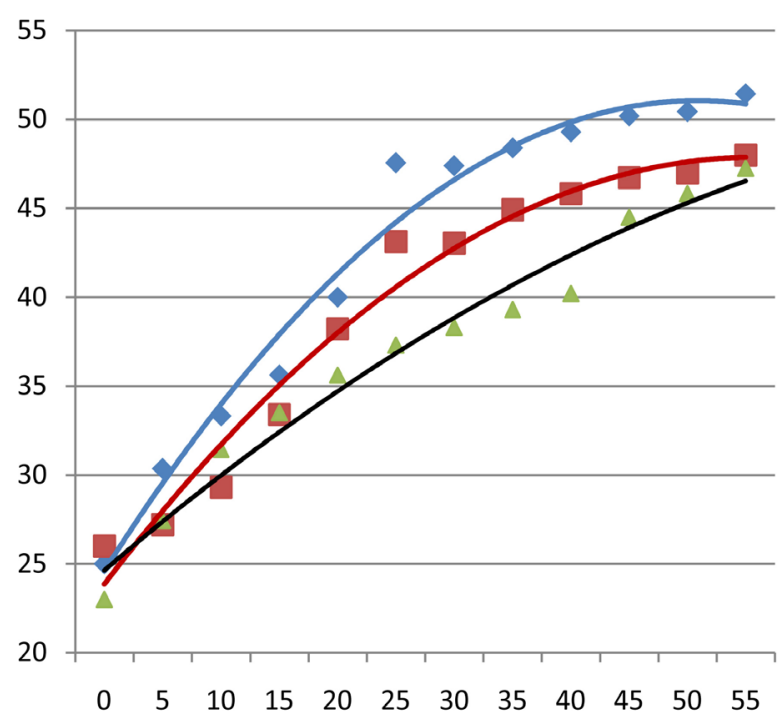

- R410A sanitary hot water mode

R22 sanitary hot water mode

$\triangle \mathrm{R} 407 \mathrm{C}$ sanitary hot water mode

Figure 20. The temperature of the sanitary hot water tank vs. the operation time with R22/R407C/R410A.

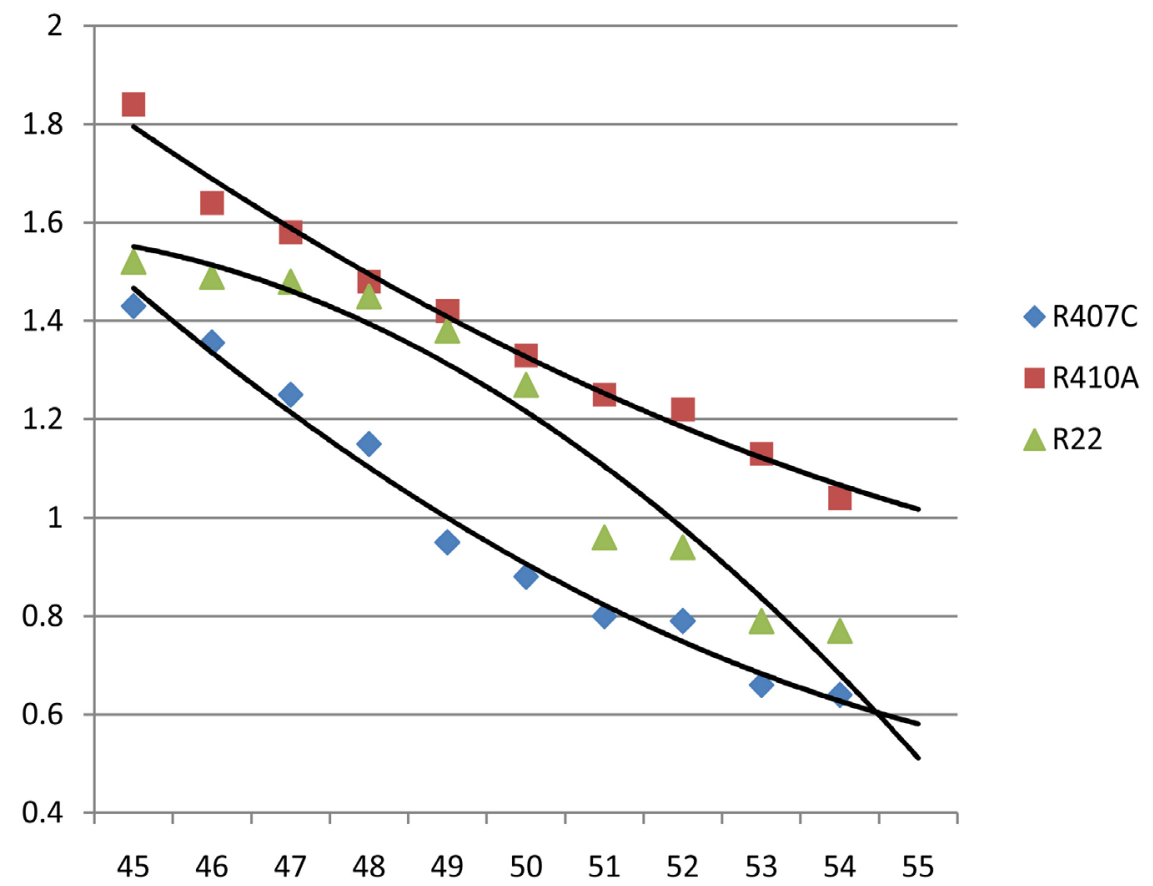

Figure 21. The exergy efficiency vs. the temperature of the sanitary hot water with R22/R407C/R410A.

systems, the analysis method, and the required assumptions are explained in details. The CCP systems with $\mathrm{R} 407 \mathrm{C} / \mathrm{R} 410 \mathrm{~A}$ and $\mathrm{CCP}$ system with $\mathrm{CO}_{2}$ trans-critical were compared to the CCP system with R22 discussed in details. The different CCP systems are made comparable by looking at the different exergy loss versus the condensing temperatures and the temperature of the sanitary hot tank versus the operating time and the COP versus the operating time and the exhaust pressure and the exergy efficiency versus the temperature of the 


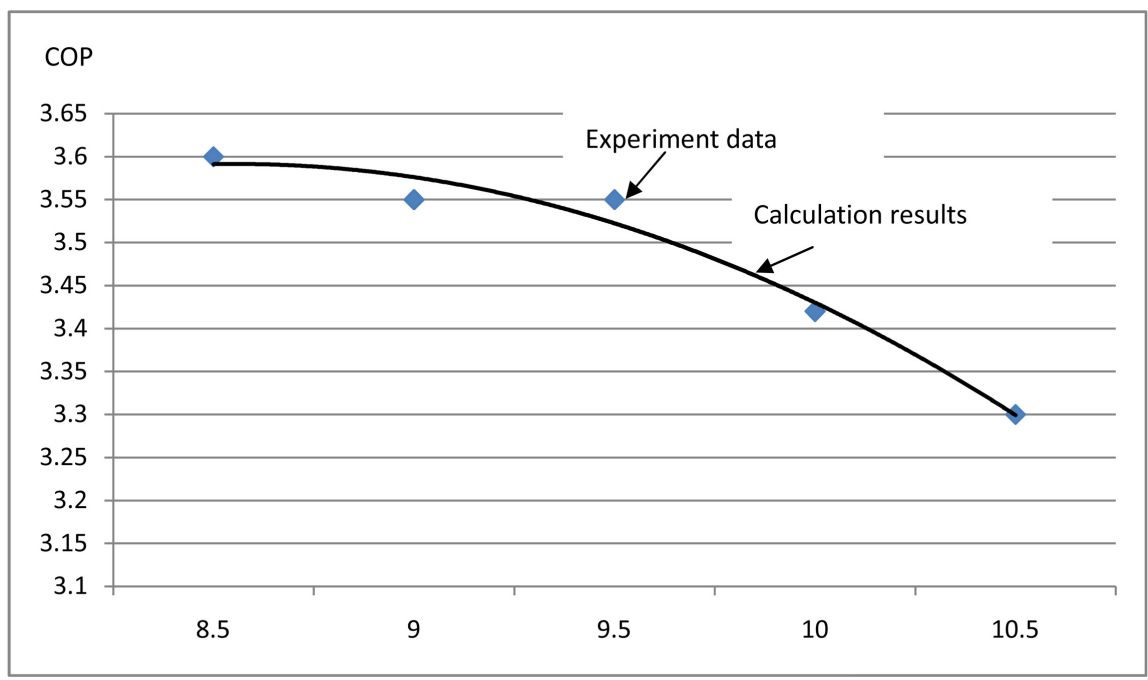

Exhaust Pressure (MPa)

Figure 22. The COP of the $\mathrm{CO}_{2}$ refrigerant mode vs. exhaust pressure.

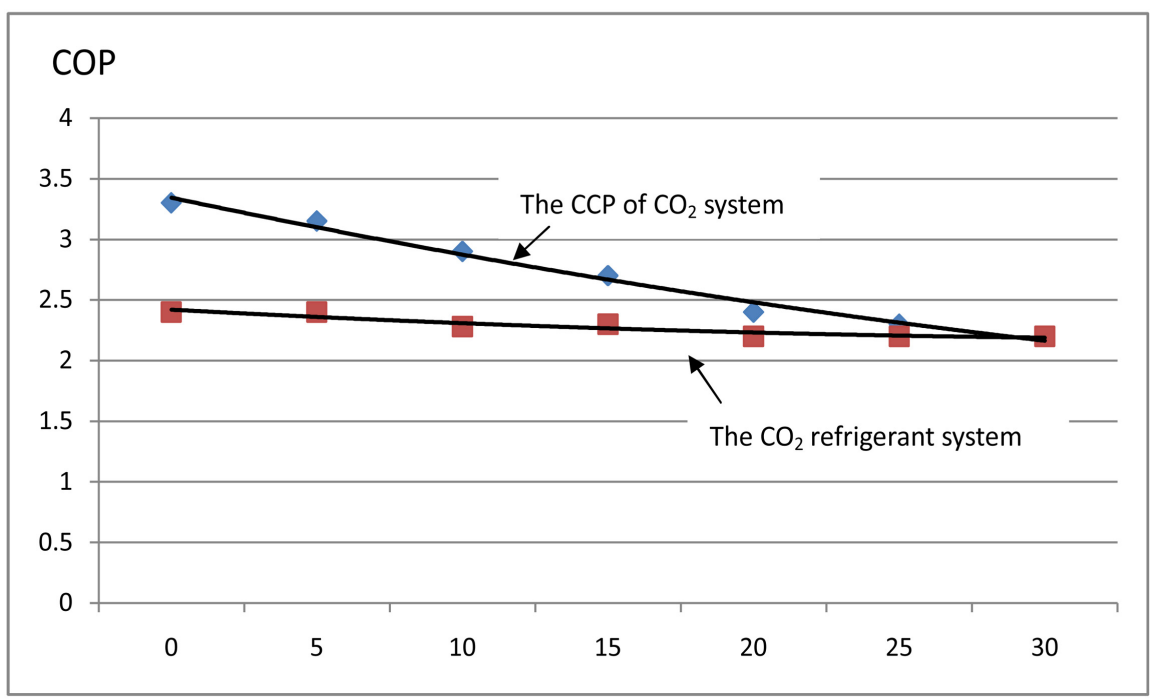

The operation time (Min)

Figure 23. The COP of CCP system with $\mathrm{CO}_{2}$ vs. the $\mathrm{COP}$ of $\mathrm{CO}_{2}$ refrigerant system.

sanitary hot tank. Theoretical modelling where the energy use of the CCP systems with $\mathrm{HFC}$ and $\mathrm{CO}_{2}$ trans-critical in a period of the sanitary hot water increased to reach the user demand was calculated.

\section{Conclusions}

The COP and exergy efficiency of a period that the sanitary hot water increases to reach the temperature that the user demands were plotted. It is the CCP system with $\mathrm{HFC}$ and $\mathrm{CO}_{2}$ trans-critical in a typical resident. The total $\mathrm{COP}$ of the CCP system with R410A is about 3\% - 5\% higher than the CCP system with R22, and the CCP system of R407C is a little lower than the R22 system due to their thermal characteristics. To the $\mathrm{CCP}$ system of $\mathrm{CO}_{2}$ trans-critical, it has advantage 


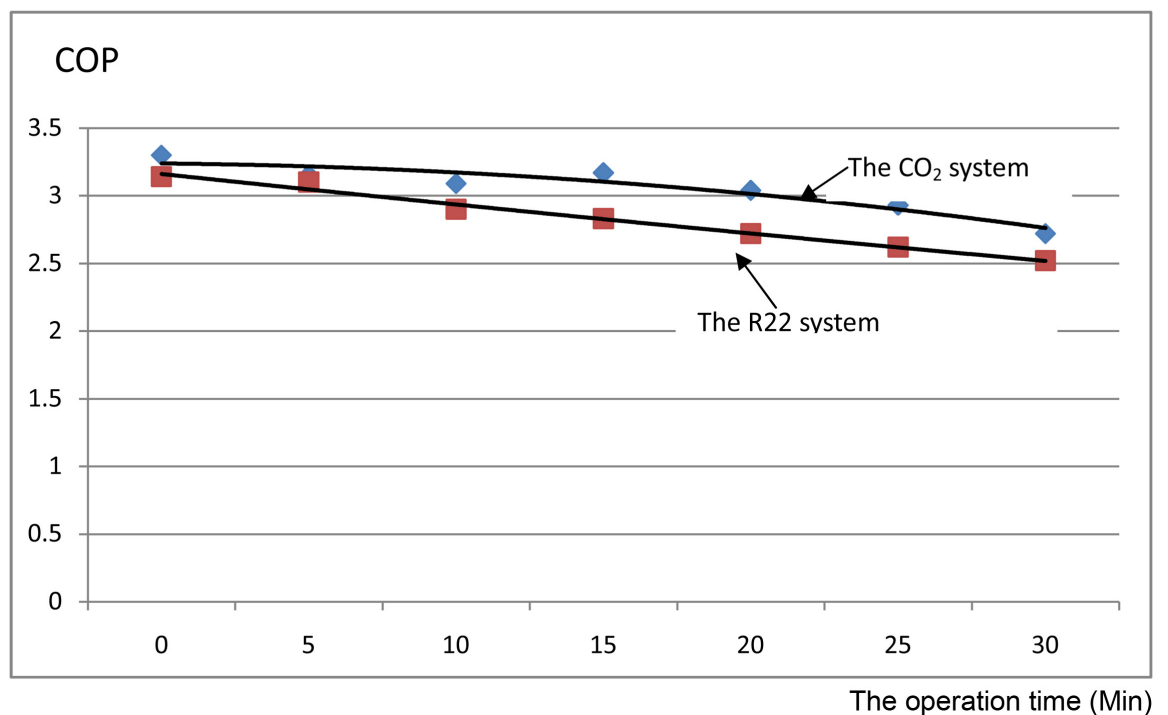

Figure 24. The COP of the $\mathrm{CO}_{2}$ system vs. the R22 system on the sanitary hot water + heating mode.

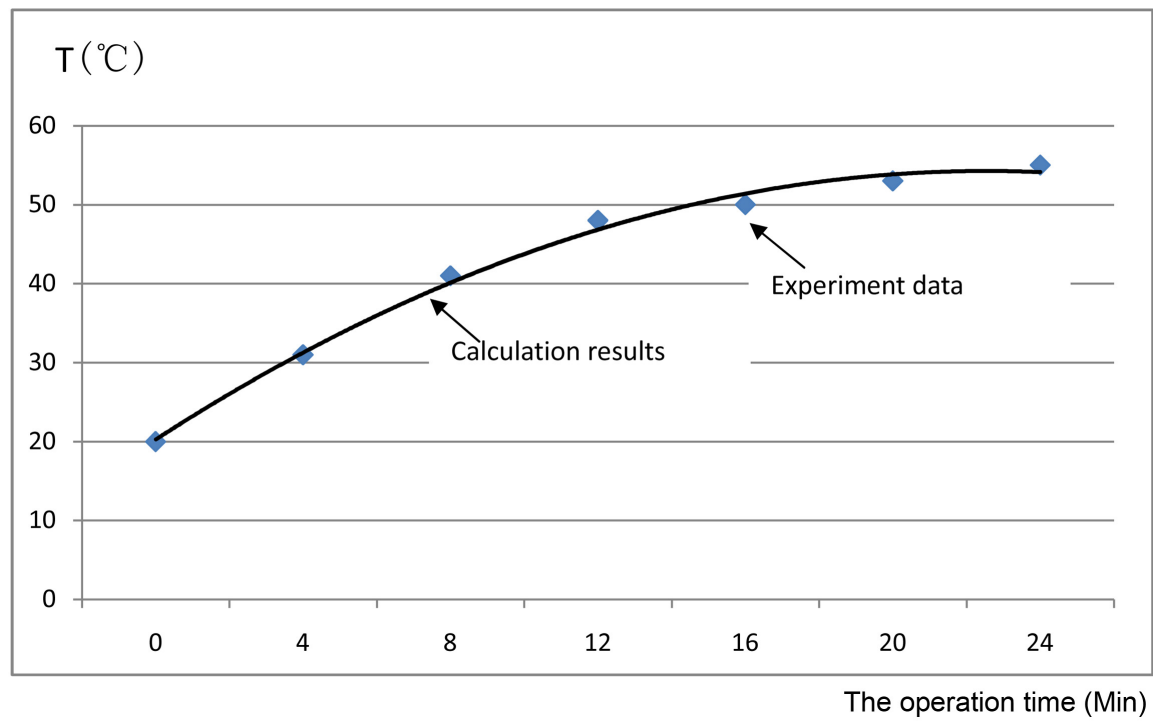

Figure 25. The outlet temperature of the sanitary hot water tank on the sanitary hot water mode with $\mathrm{CO}_{2}$.

compared to the refrigerant mode. The trend is the same with the traditional refrigerant mode. On the sanitary hot water mode, the exergy efficiency of both CCP system with $\mathrm{CO}_{2}$ and $\mathrm{R} 22$ declines with the increase of the sanitary hot water temperature that the user demands. And it is the same with $\mathrm{R} 407 \mathrm{C}$ and R410A. To reach the temperature of the sanitary hot water tank $53^{\circ} \mathrm{C}$, the $\mathrm{CO}_{2}$ trans-critic CCP system is 12 mins faster than the CCP system with R22. And the COP of the CCP system with $\mathrm{CO}_{2}$ trans-critical is higher than the CCP system with R22 at the sanitary hot water mode.

The detailed analysis done in this study proves that $\mathrm{HFC}$ and $\mathrm{CO}_{2}$ trans-critical CCP systems are more energy efficient solutions for residential 
than typical $\mathrm{HFC}$ and $\mathrm{CO}_{2}$ refrigeration systems in South of China. The analysis method and results presented in this study can be used to expand the analysis for different case studies in other climate conditions which will help verify the potential of $\mathrm{HFC}$ and $\mathrm{CO}_{2}$ trans-critical CCP solution in other countries.

\section{Acknowledgements}

The authors would like to thank the engineers, like Wei Zen, for their help in system experimentation. The authors are also grateful to the financial support of National Special Program of International Cooperation and Exchange (No. 2010DFB83650); Important and big Science Program of Hunan Province of China (Nos. 2008GK2016; 2010FJ1013); and thanks professor Jinyue Yan has given helpful advises.

\section{Conflicts of Interest}

All authors declare that they have no conflicts of interest or financial conflicts to disclose.

\section{References}

[1] Su, H., Gong, G.C. and Wang, C.G. (2017) Thermodynamic Optimization of an Irreversible Carnot Refrigerator with Heat Recovery Reservoir. Applied Thermal Engineering, 110, 1624-1634. https://doi.org/10.1016/j.applthermaleng.2016.09.013

[2] Wang, L.P., Gong, G.C. and Chen, F.H. (2012) Finite-Time Thermodynamic Simulation of Circulating Direct Condensation Heat Recovery on Chillers. The 7 th International Green Energy Conference, Dalian, March 2012, 794-803.

[3] Gong, G.C. and Chen, F.H. (2012) Thermodynamic Simulation of Condensation Heat Recovery Characteristics of a Single Stage Centrifugal Chiller in a Hotel. Applied Energy, 91, 326-333. https://doi.org/10.1016/j.apenergy.2011.08.007

[4] Zhu, Y.X. and Lin, B. (2004) Sustainable Housing and Urban Construction in China. Energy Build, 36, 1287-1297. https://doi.org/10.1016/j.enbuild.2003.11.007

[5] Ji, J., Chow, T.T., Pei, G., Dong, J. and He, W. (2003) Domestic Air-Conditioner and Integrated Water Heater for Subtropical Climate. Applied Thermal Engineering, 23, 581-592. https://doi.org/10.1016/S1359-4311(02)00228-4

[6] Adriansyah, W. (2004) Combined Air Conditioning and Tap Water Heating Plant Using $\mathrm{CO}_{2}$ as Refrigerant. Energy Build, 36, 690-695.

https://doi.org/10.1016/j.enbuild.2004.01.014

[7] (2005) Combination Water and Space Heating Systems. A Green Affordable Housing Coalition Fact Sheet, Green Affordable Housing Coalition.

[8] Lee, A.H.W. and Jones, J.W. (1997) Analytical Model of a Residential Desuperheater. Applied Energy, 57, 271-285. https://doi.org/10.1016/S0306-2619(97)00028-7

[9] Valentine, M.L. and Goldschmidt, V.W. (1989) Mathematical Model of a Refrigerant Desuperheater for Heat Recovery. ASHRAE Transactions, 95, 215-223.

[10] Ying, W.M. (1989) Performance of Room Air Conditioner User for Cooling and Hot Water Heating. ASHRAE Transactions, 95, 441-444.

[11] Lee, A.H.W. and Jones, J.W. (1996) Thermal Performance of a Residential Desuperheater/Water Heater System. Energy Conversion and Management, 37, 389-398. 
https://doi.org/10.1016/0196-8904(95)00195-6

[12] Kaushik, S.C. and Singh, M. (1995) Feasibility and Design Studies for Heat Recovery from a Refrigeration System with a Canopus Heat Exchanger. Heat Recovery Systems and CHP, 10, 665-673. https://doi.org/10.1016/0890-4332(95)90046-2

[13] Granryd, E., Ekroth, I., Lundqvist, P., Melinder, Å., Palm, B. and Rohlin, P. (2011) Refrigeration Engineering-Part I: Green Information Technology. Vol. 34, Royal Institute of Technology (KTH), Stockholm, Sweden, 223-248.

[14] Engsten, J.K. (2002) Refrigerant Leakage from Supermarkets in Sweden. Master Thesis, Royal Institute of Technology (KTH), Stockholm.

[15] Shecco. (2015) Guide to Natural Refrigerants in North America-State of the Industry. http://www.publications.shecco.com/publications/view/guide-north-america-2015

[16] Sawalha, S. (2008) Carbon Dioxide in Supermarket Refrigeration. Doctoral Thesis, Royal Institute of Technology (KTH).

[17] Cecchinato, L., Corradi, M. and Minetto, S. (2012) Energy Performance of Supermarket Refrigeration and Air Conditioning Integrated Systems Working with Natural Refrigerants. Applied Thermal Engineering, 48, 378-391. https://doi.org/10.1016/j.applthermaleng.2012.04.049

[18] Sharma, V., Fricke, B. and Bansal, P. (2014) Comparative Analysis of Various $\mathrm{CO}_{2}$ Configurations in Supermarket Refrigeration Systems. International Journal of Refrigeration, 46, 86-99. https://doi.org/10.1016/j.ijrefrig.2014.07.001

[19] Berger, U. (2011) $\mathrm{CO}_{2}$ as Standard Refrigerant: Obstacles and Lessons Learnt.

[20] Sawalha, S., Karampour, M. and Rogstam, J. (2015) Field Measurements of Supermarket Refrigeration Systems. Part I: Analysis of $\mathrm{CO}_{2}$ Trans-Critical Refrigeration Systems. Applied Thermal Engineering, 87, 633-647. https://doi.org/10.1016/j.applthermaleng.2015.05.052

[21] Tamilarasan, M.L. (2009) Field Measurements, Evaluation and Comparison of Supermarket Refrigeration systems. Master Thesis, Royal Institute of Technology.

[22] Klein, S.A. (2015) Engineering Equation Solver (EES) V9, F-Chart Software, Madison, USA. http://www.fchart.com

[23] da Silva, A., Bandarra Filho, E.P. and Antunes, A.H.P. (2012) Comparison of a R744 Cascade Refrigeration System with R404A and R22 Conventional Systems for Supermarkets. Applied Thermal Engineering, 41, 30-35. https://doi.org/10.1016/j.applthermaleng.2011.12.019 


\section{Nomenclature}

$C_{p} \quad$ Special heat capacity of constant pressure $\left(\mathrm{kj} \cdot \mathrm{kg}^{-1} \cdot{ }^{\circ} \mathrm{C}^{-1}\right)$

d Diameter

$E_{w} \quad$ Work input to the refrigeration cycle

$E_{c h} \quad$ Exergy of the chilled water

$E_{\text {shw }} \quad$ Exergy of the sanitary hot water

$\dot{e}_{w} \quad$ Exergy of the chilled water at cycle $i$

$\dot{e}_{c h w i} \quad$ Exergy of the chilled water at cycle $i$

$H_{C} \quad$ Enthalpy at state $\mathrm{C}$

$H_{4^{\prime}} \quad$ Enthalpy of state $4^{\prime}$

$\dot{H}_{c} \quad$ Enthalpy rate at state $\mathrm{C}$

$H_{X} \quad$ Enthalpy at state $\mathrm{X}$

$\dot{H}_{x} \quad$ Enthalpy rate at state $\mathrm{X}$

$h_{1} \quad$ Specific enthalpy at state 1

$h_{2} \quad$ Specific enthalpy at state 2

$h_{3} \quad$ Specific enthalpy at state 3

$h_{4} \quad$ Specific enthalpy at state 4

$h_{x i} \quad$ Specific enthalpy at state X of cycle $i$

$\dot{I}_{\text {cond }} \quad$ Exergy loss rate of the condenser

$I_{\text {shwi }} \quad$ Exergy loss of sanitary hot water at cycle $i$

$m_{\text {shw }} \quad$ Mass flow of sanitary hot water

$m_{\text {ref }} \quad$ Mass flow rate of refrigerant

$m_{e v} \quad$ Mass flow of the evaporator

$P$

$P_{r l}$

$Q_{c}$

Pressure

Prandtl number of the liquid $\mathrm{CO}_{2}$

Total condensation heat

$Q_{\text {cond }}^{\prime} \quad$ The heat exhaust to sanitary hot water unit

$Q_{\text {hroi }} \quad$ Heat exhaust to the environment at cycle $i$

$Q_{\text {loss }} \quad$ Heat exhaust to the environment

$Q_{\text {refi }} \quad$ Heat exhaust by the refrigerant at cycle $i$

$Q_{\text {shw }} \quad$ Heat absorbed by sanitary hot water

$Q_{\text {shwi }} \quad$ Heat absorbed by the sanitary hot water at cycle $i$

$\dot{Q}_{c h w i} \quad$ Heat absorbed rate by chilled water at cycle $i$

$\dot{Q}_{\text {cond }}^{\prime} \quad$ Heat recovered rate by the sanitary hot water system

$\dot{Q}_{s h w} \quad$ Heat exhaust rate to sanitary hot water system

$R_{e} \quad$ Reynard number of the liquid $\mathrm{CO}_{2}$
Specific entropy

Specific entropy of initial temperature of the input water

Specific entropy at the state 3

Specific entropy at the state $\mathrm{X}$

$t \quad$ Operating time

$T \quad$ Temperature

$T_{0} \quad$ Temperature of the initial water

$T_{C} \quad$ Temperature at state C

$T_{i} \quad$ Temperature at cycle $i$

$T_{i-1} \quad$ Temperature at cycle $i-1$

$\dot{W}_{i} \quad$ Power input at cycle $i$

$X_{t t} \quad$ Turbulence liquid

Greek

letters

$\eta \quad$ Exergy efficiency of the system

$\rho \quad$ Density

Subscripts 0 Reference state

C State C

Ch Chilled water

Comp Compressor

Cond Condenser

$i \quad$ Cycle $i$

Ref Refrigerant

$\mathrm{X} \quad$ State $\mathrm{X}$

CCP Compound condensation process

COP Coefficient of performance

AC/HP Air-condition/heat pump 